This item was submitted to Loughborough's Research Repository by the author.

Items in Figshare are protected by copyright, with all rights reserved, unless otherwise indicated.

\title{
A numerical study of capillary pressure - saturation relationship for supercritical carbon dioxide (CO2) injection in deep saline aquifer
}

PLEASE CITE THE PUBLISHED VERSION

http://dx.doi.org/10.1016/j.cherd.2014.04.020

\section{PUBLISHER}

(c) The Institution of Chemical Engineers. Published by Elsevier B.V.

\section{VERSION}

AM (Accepted Manuscript)

\section{LICENCE}

CC BY-NC-ND 4.0

\section{REPOSITORY RECORD}

Khudaida, Kamal, and Diganta Bhusan Das. 2014. "A Numerical Study of Capillary Pressure - Saturation Relationship for Supercritical Carbon Dioxide (CO2) Injection in Deep Saline Aquifer”. figshare. https://hdl.handle.net/2134/14532. 
This item was submitted to Loughborough's Institutional Repository (https://dspace.lboro.ac.uk/) by the author and is made available under the following Creative Commons Licence conditions.

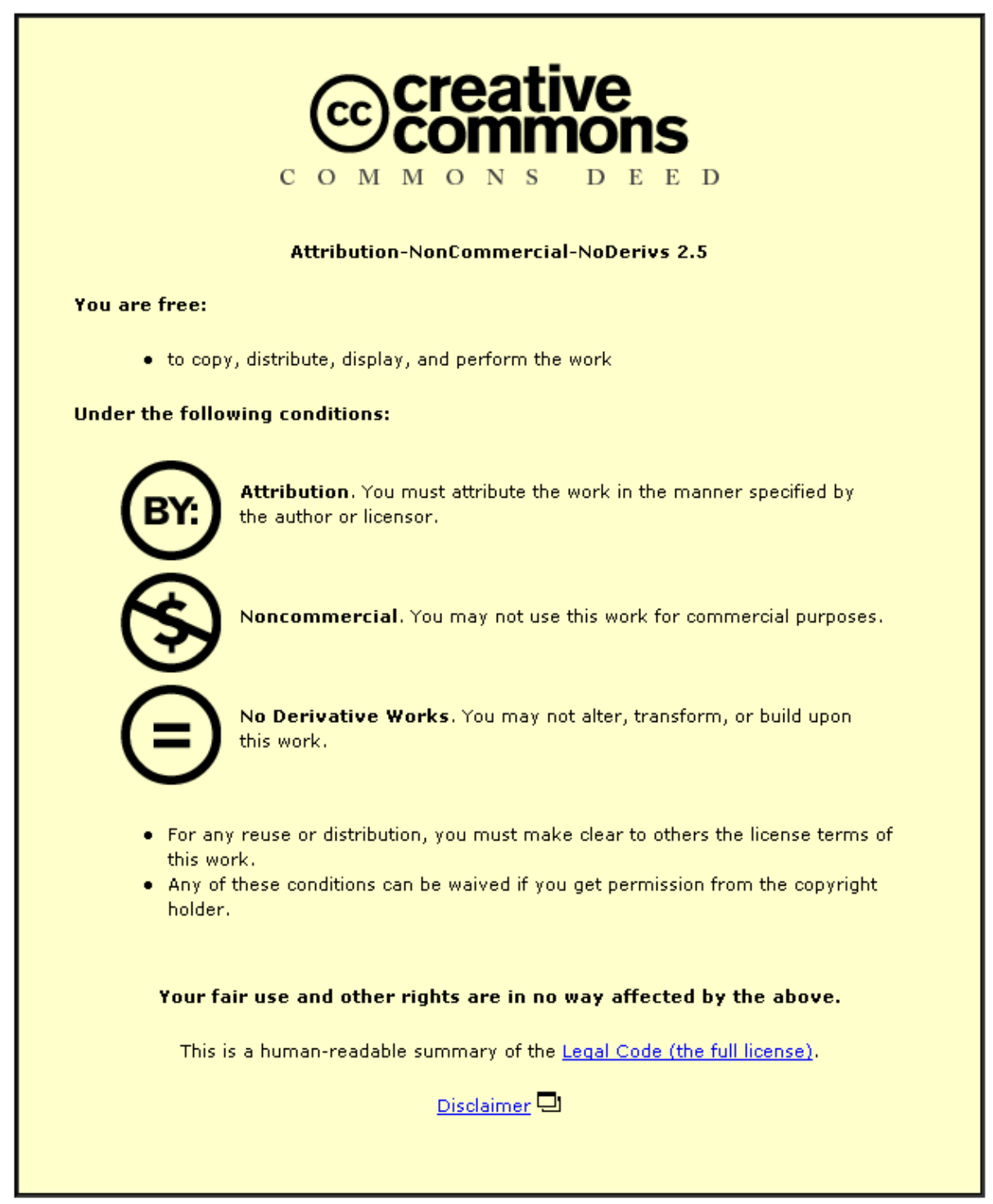

For the full text of this licence, please go to: http://creativecommons.org/licenses/by-nc-nd/2.5/ 
1 A numerical study of capillary pressure-saturation relationship for supercritical carbon dioxide $\left(\mathrm{CO}_{2}\right)$ injection in deep saline aquifer

3

4 Kamal Khudaida, Diganta Bhusan Das*

5

Department of Chemical Engineering, Loughborough University, Loughborough LE11 3TU, UK ( ${ }^{\star}$ Corresponding author: Email: D.B.Das@lboro.ac.uk)

\section{Abstract}

Carbon capture and sequestration (CCS) is expected to play a major role in reducing greenhouse gas in the atmosphere. It is applied using different methods including geological, oceanic and mineral sequestration. Geological sequestration refers to storing of $\mathrm{CO}_{2}$ in underground geological formations including deep saline aquifers (DSAs). This process induces multiphase fluid flow and solute transport behaviour besides some geochemical reactions between the fluids and minerals in the geological formation. In this work, a series of numerical simulations are carried out to investigate the injection and transport behaviour of supercritical $\mathrm{CO}_{2}$ in DSAs as a two-phase flow in porous media in addition to studying the influence of different parameters such as time scale, temperature, pressure, permeability and geochemical condition on the supercritical $\mathrm{CO}_{2}$ injection in underground domains. In contrast to most works which are focussed on determining mass fraction of $\mathrm{CO}_{2}$, this paper focuses on determining $\mathrm{CO}_{2}$ gas saturation (i.e., volume fraction) at various time scales, temperatures and pressure conditions taking into consideration the effects of porosity/permeability, heterogeneity and capillarity for $\mathrm{CO}_{2}$-water system. A series of numerical simulations is carried out to illustrate how the saturation, capillary pressure and the amount of dissolved $\mathrm{CO}_{2}$ change with the change of injection process, hydrostatic pressure and geothermal gradient. For example, the obtained results are used to correlate how increase in the mean permeability of the geological formation allows greater injectivity and mobility of $\mathrm{CO}_{2}$ which should lead to increase in $\mathrm{CO}_{2}$ dissolution into the resident brine in the subsurface.

Keywords: geological sequestration, two-phase flow, capillary pressure, porous media, $\mathrm{CO}_{2}$ sequestration, deep saline aquifer, $\mathrm{CO}_{2}$ sequestration

\section{Introduction}

Carbon sequestration is a technique for managing carbon dioxide $\left(\mathrm{CO}_{2}\right)$ that has been emitted into the atmosphere by various activities, e.g., combustion of carbon-based fuels. It is a relatively new concept that had been developed to address the problem of global warming, 
which is attributed to high levels of atmospheric $\mathrm{CO}_{2}$. In a more specific approach, geological sequestration aims to inject supercritical $\mathrm{CO}_{2}$ into porous formations underground while attempting to prevent leakage of $\mathrm{CO}_{2}$ to the surface again. This method can be applied to declining oil fields, un-minable coal seams as well as deep saline aquifers (DSAs). Injecting $\mathrm{CO}_{2}$ into DSAs is considered to be one of the most feasible sequestration methods of $\mathrm{CO}_{2}$. From a fluid mechanics point of view, injecting supercritical $\mathrm{CO}_{2}$ into geological formations can be treated as a two-phase flow in a porous medium (Tsang et al., 2008). Supercritical $\mathrm{CO}_{2}$ is considerably denser than the gaseous $\mathrm{CO}_{2}$ phase but has lower density and viscosity than the occupant brine in the porous space. As a result of the differences of fluid densities, supercritical $\mathrm{CO}_{2}$ migrates buoyantly towards the upper confining layer. The preferred depths to inject $\mathrm{CO}_{2}$ are greater than $800 \mathrm{~m}$ (Prevost et al., 2005) as they provide the required conditions above the critical points of $\mathrm{CO}_{2}$ for it to stay in supercritical phase. This increases the storage capacity of the site because more $\mathrm{CO}_{2}$ can be stored within a specific volume.

It must be emphasised that there are particular conditions, which the geological formation must meet for $\mathrm{CO}_{2}$ storage to be successful. According to Bachu and Bennion (2008), three basic conditions must be met, namely, (i) capacity, i.e., the geological media must have the capacity to allow the anticipated amount of $\mathrm{CO}_{2}$ over the duration of the project operation; (ii) injectivity, i.e., the media must be able to allow the $\mathrm{CO}_{2}$ at its injection rate and, (iii) confinement, i.e., the media must be able to impede leakage of $\mathrm{CO}_{2}$ from the storage zone or minimize leakage to the tolerable levels. Furthermore, geological storage of $\mathrm{CO}_{2}$ is determined by four foremost trapping mechanisms as discussed below.

(a) Structural trapping, which takes place when $\mathrm{CO}_{2}$ gas becomes immobile in the porous sedimentary layers with existed brine by impermeable barriers (White et al., 2013).

(b) Residual trapping that takes place as a result of the hysteresis effect when the saturation direction is reversed after the injection process stops and, the existing brine moves back and tries to displace $\mathrm{CO}_{2}$ in the pores (Ide et al., 2007).

(c) Solubility trapping takes place when the injected $\mathrm{CO}_{2}$ dissolves in the resident fluid and increases the acidity and density of the brine creating convective currents that allow the denser brine with high concentration of $\mathrm{CO}_{2}$ to settle at the bottom part of the aquifer trapping the $\mathrm{CO}_{2}$ more securely (Silin et al. 2009).

(d) Mineral trapping occurs when the dissolved $\mathrm{CO}_{2}$ reacts with the brine producing carbonic acid that reacts with the dissolved ions within the aquifer brine and minerals forming the host rock resulting in chemical precipitation of solid carbonate minerals (Beni et al., 2012). 
Modelling of underground injection of $\mathrm{CO}_{2}$ primarily represents modelling a system of twophase flow in porous media which requires one to identify the relevant parameters. These parameters describe various physical and chemical properties of the geological formation such as entry pressure (depending on pore/particle size of the domain), hydrodynamic conditions (e.g., pressure difference, groundwater velocity), fluid properties, permeability, chemical species from geochemical reactions and fluid/fluid interfacial mass transfer (Ide et al., 2007). Considerable uncertainty may however exist with regards to the formation-related parameters because of the difficulty in collecting sufficient data across the huge areas that should be taken into account for any geologic sequestration project. A number of studies have been conducted to determine the capillary pressure-saturation-relative permeability relationships for subsurface injection of $\mathrm{CO}_{2}$ into porous media (e.g., Bachu et al., 1994; Pruess et al., 2003; Kumar et al., 2005; Knauss et al., 2005; Juanes et al., 2006; Birkholzer et al., 2009; Schnaar and Digiulio, 2009). They demonstrate that computational models are able to replicate complex formation heterogeneities by employing statistical routines; residual $\mathrm{CO}_{2}$ trapping and hysteretic relative permeability curves, dissolution reactions and mineral precipitation and others. For example, Nordbotten et al. (2004) analytically described the time evolution of the $\mathrm{CO}_{2}$ plume dominated by viscous forces with irrelevant effects of the $\mathrm{CO}_{2}$ buoyancy forces using a simplified form of Buckley-Leverett equation. They utilized their modelling results to inspect the accuracy/implication of assuming constant properties for the fluids in the storage formation and discussed some cases where buoyancy and non-zero residual saturations have more influence on the mobility of $\mathrm{CO}_{2}$ plume in addition to the effects of $\mathrm{CO}_{2}$ dissolution in the existing brine.

One of the critical issues in $\mathrm{CO}_{2}$ geological sequestration is the phase transition from liquid or supercritical to gas according to the temperature and pressure changes during the injection progression. Therefore, numerical simulation for $\mathrm{CO}_{2}$ sequestration in saline aquifers should have the ability to envisage when the $\mathrm{CO}_{2}$ phase transition occurs. It must also be able to determine the buoyancy and viscous forces influence on the fluid flow and, $\mathrm{CO}_{2}$ dissolution in the aqueous fluid (White and Oostrom, 2003). Though capillarity plays a crucial role in assessment of saline aquifers for $\mathrm{CO}_{2}$ sequestration, there is not much real (field) data available about the behaviour of $\mathrm{CO}_{2}$-brine flow system in the porous rocks. Plug and Bruining (2007) developed a laboratory scale method to investigate the static capillary pressure change as a function of saturation at different pressure and temperature conditions. They examined the influence of $\mathrm{CO}_{2}$ dissolution in water by comparing its behaviour to the behaviour of nitrogen $\left(\mathrm{N}_{2}\right)$ under the same conditions and observed that the residual water saturation $\left(\mathrm{S}_{\mathrm{wc}}\right)$ for $\mathrm{CO}_{2}$ is much smaller than that for $\mathrm{N}_{2}$ due to the difference in interfacial tension. 
Capillary trapping, which is also called residual trapping, is closely related to the capillary forces between $\mathrm{CO}_{2}$ and resident fluid at the scale of the grains of reservoir rock which is controlled by interfacial forces, pore size and wettability (Alkan et al., 2010). Experimental studies conducted by Bennion and Bachu (2008), and Plug and Bruning (2007) reported that permeability and capillarity are influenced by interfacial forces and wettability of $\mathrm{CO}_{2}$-brine-rock systems. Another study on $\mathrm{CO}_{2}$ sequestration has been conducted by Bickle et al. (2007) who modelled $\mathrm{CO}_{2}$ flow behaviour in Sleipner field in the North Sea. They used a theoretical model and validated it with experimental results by Lyle et al. (2005) to characterise the gravity flow in porous media. To attain their solutions they employed a number of assumptions, e.g., neglecting the motion of the existing fluid within the hosting formation and ignored both capillary and viscous forces in the fluid flow system which exhibited some limitations in the applicability of their solutions. Bickle et al. (2007) concluded that the radius of accumulated $\mathrm{CO}_{2}$ ponds in the subsurface increases linearly with the square-root of the elapsed time. They observed an increase in $\mathrm{CO}_{2}$ input in higher layers of the domain with a decrease in lower ones due to the leakage into the upper structures of the modelled formation. Their solutions provide important predictions on $\mathrm{CO}_{2}$ behaviour with no need to carry out full simulation for any potential storage sites.

Unlike most conventional approaches for determining capillary pressure relationships which are based on equilibrium flow conditions (i.e., time derivative of fluid saturation is zero), dynamic capillary pressure effects have been shown to have a great influence on two-phase flow in porous media (Helmig et al., 2007; Mirzaei and Das, 2007; Hanspal and Das, 2012). A number of fundamental studies (e.g., Oung et al., 2005; Manthey et al., 2005; Bottero et al., 2006) have investigated the dynamic capillary pressure effects in two-phase flow systems, and this gives rise to the possibility of applying these understanding to determine if these effects are significant for supercritical $\mathrm{CO}_{2}$ flow in the geological formation as well.

In addressing most of the above issues, the main goal of this study is to carry out a simulation study to determine static and dynamic capillary pressures for $\mathrm{CO}_{2}$-water system as a function of saturation for different permeability and heterogeneity at various time scales, temperature and pressure conditions in order to evaluate the implications of different $\mathrm{CO}_{2}$ injection strategy and its storage capacity in briny aquifers. For this purpose a series of numerical simulations are to be carried out under various pressure, temperature, heterogeneity and injection rate conditions. It is envisaged that this would help the prediction of the right $\mathrm{CO}_{2}$ injection process and $\mathrm{CO}_{2}$ behaviour within the aquifer formation during sequestration life time which has a vast impact on the energy cost and storage process safety. It is believed that this study will provide better 


\section{Modelling Approach}

\subsection{Main Equations}

In this work the injection of $\mathrm{CO}_{2}$ into saline aquifers is defined to represent the flow of two immiscible fluids, namely, water (brine) as a wetting phase and $\mathrm{CO}_{2}$ as a non-wetting phase in a porous medium where supercritical $\mathrm{CO}_{2}$ replaces the existing fluid in a process called drainage.

\subsubsection{Mass and Momentum Conservation Equations}

Modelling $\mathrm{CO}_{2}$ injection into geological formation is governed by the equations of mass and momentum conservation.

The conservation of momentum is described by the following form of Darcy's law:

$\frac{\partial\left(s_{\alpha} \phi \rho_{\alpha}\right)}{\partial t}+\nabla \cdot\left(\rho_{\alpha} v_{\alpha}\right)-\rho_{\alpha} q_{\alpha}=0$

where $S_{\alpha}$ is the phase $\alpha$ (water or $\mathrm{CO}_{2}$ ) saturation, $\phi$ is the porosity, $\rho_{\alpha}$ is the density, $t$ refers to the elapsed time, $v_{\alpha}$ is the average pore velocity of the phase and $q_{\alpha}$ refers to the phase flux.

162

From the generalized Darcy's law (equation of momentum), velocity vector $v_{\alpha}$ is $b$ calculated as

$v_{\alpha}=-\frac{k_{r \alpha}}{\mu_{\alpha}} K\left(\nabla p_{\alpha}-\rho_{\alpha} g\right)$

$k_{r \alpha}$ identifies the relative permeability for the phase $\alpha$ (water or $\mathrm{CO}_{2}$ ), $\mu$ refers to the dynamic velocity, $p_{\alpha}$ identifies the pressure, $K$ is the tensor of absolute permeability (defined to be isotropic) and $g$ the vector of gravity. The phase permeability (effective permeability) $\left(k_{a}\right)$ is related to the relative permeability $\left(k_{r \alpha}\right)$ as:

$k_{\mathrm{r \alpha}}=\frac{k_{\alpha}}{K}$

where $K$ signifies the domain permeability for a single-phase flow (the absolute permeability).

By substituting equation (2) in equation (1) the following general form of mass conservation equation is obtained for both fluid phases:

$$
\frac{\partial\left(s_{\alpha} \phi \rho_{\alpha}\right)}{\partial t}-\nabla \cdot\left(\rho_{\alpha} \frac{k_{r \alpha}}{\mu_{\alpha}} K\left(\nabla p_{\alpha}-\rho_{\alpha} g\right)\right)-\rho_{\alpha} q_{\alpha}=0
$$

\subsubsection{Constitutive Relationships}

177 The two fluid flow process is dominated by capillary pressure $\left(P_{C}\right)$ - saturation $\left(S_{w}\right)$ - relative 178 permeability $\left(k_{r}\right)$ relationships because any decrease in the wetting phase saturation results in non-wetting fluid retreatment into smaller pores which increases the capillary pressure. In a two 
phase flow the capillary pressure is defined as the difference between the average phase pressures of non-wetting $(n w)$ and wetting $(w)$ phases,

$$
P_{c=} P_{n w}-P_{w}
$$

One of the most common formulations used to determine $P_{c}-S_{w}-K_{r}$ relationships is BrooksCorey function (Brooks and Corey, 1964), in which the displacement pressure of the wetting fluid from the largest pore $\left(P_{d}\right)$ is involved while this pressure has been ignored by other authors for fully saturated porous media. The relationship defines the effective saturation as:

$S_{e w}=\left(\frac{P_{c}}{P_{d}}\right)^{-\lambda}$

$$
\text { for } P_{c}>P_{d}
$$

$S_{e w}=1$

for $P_{c} \leq P_{d}$

$S_{e w}=\frac{\left(S_{w}-S_{w r}\right)}{\left(1-S_{w r}\right)}$

for $0 \leq S_{e w} \leq 1$

Where, $\left(S_{\text {ew }}\right)$ denotes the effective water saturation, $\left(S_{w r}\right)$ is the residual water saturation, $\left(P_{d}\right)$ represents entry (displacement) pressure, $(\lambda)$ is the pore size distribution index.

Brooks-Corey correlations in conjunction with the Burdine theorem (Burdine, 1953) are used to define the relative permeability-saturation relationships for wetting $(w)$ and non-wetting (nw) phases.

$k_{r w}=S_{e w}^{\frac{2+3 \lambda}{\lambda}}$

$k_{r n w}=\left(1-S_{e w}\right)^{2}\left(1-S_{e w}^{\frac{2+\lambda}{\lambda}}\right)$

The coupled equations are solved for the primary variables where the porous domain is assumed to be a rigid rock and both fluids are defined as incompressible. Furthermore, the dynamic viscosities of the fluids are assumed to be constant and all source and sink terms are ignored.

\subsection{Simulation Approach}

The scope of this research is to simulate the process of injecting $\mathrm{CO}_{2}$ as a supercritical fluid into DSAs. It focuses on the flow of multiphase fluid $\left(\mathrm{H}_{2} \mathrm{O}-\mathrm{CO}_{2}-\mathrm{NaCl}\right)$ in a porous media for which STOM32 (STOMP-CO ${ }_{2}$ ) operational mode of STOMP (subsurface transport over $\underline{\text { multiple }}$ phases) simulation code is used. In this mode water (brine) is the wetting phase and $\mathrm{CO}_{2}$ is a non-wetting fluid which is injected at different pressure rates into the porous domain which is fully saturated with water (brine). This leads to a situation where $\mathrm{CO}_{2}$ drains water out of the domain in a process called drainage followed by an imbibition process when $\mathrm{CO}_{2}$ injection ends 
and water flows back into the domain to replace $\mathrm{CO}_{2}$ in the domain pores leaving some traces of it trapped. This operational mode is able to incorporate buoyancy and viscous forces driven flow, $\mathrm{CO}_{2}$ dissolution in aqueous fluid, phase transition, dispersion and diffusivity of the gas and uses the finite volume technique to numerically simulate the process. These are discussed in detail by White and Oostrom (2003) and are not repeated in this paper. However it should be mentioned that STOMP-CO $\mathrm{CO}_{2}$ simulator is written in FORTRAN 90 with a capability of dynamic memory allocation for faster execution. The collection of source files is required to be compiled into an executable file that can be used on various computing platforms including Linux and Windows to read the input file that is created by the user including a number of cards that contain calculation instructions and required parameters to solve the simulation problem. The code has been effectively optimized for workstations (HP, IBM, Sun) in addition to mainframes. The speed and memory requirements for running STOMP-CO $\mathrm{CO}_{2}$ executable files depend on the complexity of the problem and computational grid refinement. There is no minimum memory or processor speed provided by the developer. However, from our experience it has been found out that the code better functions on UNIX operating system with $2.4 \mathrm{GHz}$ CPU and $1 \mathrm{~GB}$ memory. STOMP- $\mathrm{CO}_{2}$ is utilized to numerically solve the coupled conservation equations (water mass, $\mathrm{CO}_{2}$ mass and $\mathrm{NaCl}$ mass) by converting them to algebraic equations using finite volume method (FVM) and Euler-backward time differencing for spatial and temporal discretizations, respectively. Backword Euler method is a first order time stepping method that makes an error of $\Delta t^{2}$ for each time step. This method offers more stability and accuracy than forward Euler method especially for problems with large and nonlinear functions like diffusion equations. The produced algebraic equations in the discretised equations are closed using a number of constitutive relationships as explained in section 2 and solved using Newton-Raphson iteration to resolve their nonlinearities (White and Oostrom, 2003).

\subsection{Initial and Boundary Conditions}

The domain is considered to be anisotropic and almost fully saturated with brine before injecting supercritical $\mathrm{CO}_{2}$ in the centre. The initial condition for all simulation conditions are shown in Table 4. We generate two-phase conditions within the computational domain by setting the aqueous saturation value at 0.9999 as an initial condition for the employed equations of state in the simulation code (e.g., Kelvin equation (Nitao, 1988), and the formulation by Battistelli et al. (1997)) which take into account the changes in thermodynamic properties of the fluid phases as the simulation conditions change. The non-wetting fluid $\left(\mathrm{CO}_{2}\right)$ saturation was assumed to be 1.0 at the injection source at the outer wall of the reservoir and 0.00001 in the rest of the computation domain as initial condition for the reason above. It is injected into the lower 3 grid cells (i.e. $30 \mathrm{~m}$ from the bottom of the domain). Vertically zero flux is considered for aqueous phase at the well case as inner boundary while the outer boundary was assumed to be infinite 
with zero flux for gas phase. Horizontally zero flux is considered at the upper and lower surfaces which force the injected gas to spread laterally. For both dynamic and static conditions, fluids saturation, pressure and volume are measured at each node and the $\mathrm{CO}_{2}$ saturation is plotted versus simulation time. This procedure is repeated twice: once for sandstone (coarse) and another for Wechselfolgen (fine) homogeneous domains. This procedure is repeated twice: once for sandstone (coarse) and another for Wechselfolgen (fine) homogeneous domains.

\subsection{Dynamic and Quasi-static Simulations}

In this research work, simulations are carried out by injecting $\mathrm{CO}_{2}$ into the centre of the computational domain which is initially fully saturated with brine. The gas pressure is defined to be zero all over the domain. The $\mathrm{CO}_{2}$ injection starts at $32 \mathrm{MPa}$ and increased at a rate of 0.1 MPa every 0.5 year for 20 years for quasi-static simulations. This increment in injection pressure increases the capillary pressure $\left(P_{c}\right)$ in the domain until it reaches the displacement pressure $\left(P_{d}\right)$ when the injected $\mathrm{CO}_{2}$ starts displacing the existing brine and continues till a steady state is reached when average values of aqueous saturation and capillary pressure are calculated to give a single point for the $P_{c}-S_{w}$ relationships. This procedure is repeated for each time step from which the $P^{c}-S_{w}$ curves are produced. For dynamic simulations the imposed injection pressure is increased to $36 \mathrm{MPa}$ in one step and maintained till the end of injection period.

\subsection{Capillary Pressure and Saturation Averaging}

From the locally predicted values of saturation and pressure at each grid node for each time step $\left(t_{n}\right)$ the volume-weighted average water saturation $\left(S_{w}\right)$ and saturation-weighted average capillary pressure $\left(P_{c}\right)$ values for the whole domain are determined using the following equations.

The average saturation at any time step $\left(t_{n}\right)$ is calculated by;

$$
\left.S_{w}\right|_{t n}=\frac{\left.\sum_{j=1}^{m} S_{w j} V_{j}\right|_{t n}}{\sum_{j=1}^{m} V_{j}}
$$

And the average capillary pressure is calculated by;

$$
\left.P^{c}\right|_{t n}=\left.\left[\frac{\sum_{j=1}^{m}\left(1-S_{w j}\right) P_{n w j}}{\sum_{j=1}^{m}\left(1-S_{w j}\right)}-\frac{\sum_{j=1}^{m} S_{w j} P_{w j}}{\sum_{j=1}^{m} S_{w j}}\right]\right|_{t n}
$$

Where, $V_{j}$, is the volume of node $j$, and, $S_{w j}, P_{w j}$ and $P_{n w j}$ denote water saturation, water pressure and $\mathrm{CO}_{2}$ pressure at node $j$, respectively. 
The time derivative of saturation dependency can be calculated from the average saturation values calculated from equation (13) as follows:

$\left.287 \frac{\partial s}{\partial t}\right|_{s_{w}} t_{n}=\frac{s_{w}\left|t_{n+1}-S_{w}\right|_{n-1}}{t_{n+1}-t_{n-1}}$

As shown in equations (11) and (12), both calculated average values are based on water saturation and, hence, they are called saturation-weighted averages (Mirzaei and Das, 2007; Hanspal and Das, 2012).

292

Conventional theories (Collins, 1961; Scheidegger, 1974; Bear and Verruijt, 1987; Helmig, 1997) define capillary pressure as a function of fluid saturation only for fluids at equilibrium conditions. However, this is not always the case as fluids might not flow under steady conditions especially at early stages of flow when the change rate of saturation is thought to be high. Therefore, it has been suggested by many authors that an additional term ought to be added to the capillary pressure equation (5) for dynamic fluid flow in porous media (Hassanizadeh and Gray, 1993a; Beliaev and Schotting, 2002; Dahle et al., 2005; Hanyga and Seredynska, 2005; Oung et al., 2005).

301

In this study we will be investigating the dynamic effects at a field-scale domain. The additional term is called the dynamic coefficient $(\tau)$ which represents dynamic capillary pressure effect on the flow behaviour and is determined from the slope of a linear relationship between the capillary pressures at dynamic and static flow conditions and the time derivative of saturation as shown in equation (14):

where $P_{c, \text { dyn }}$ and $P_{c, \text { stat }}$ represent dynamic and static capillary pressures calculated at a specific value of saturation $(s)$, respectively. The dynamic coefficient has been used by many previous workers (e.g. Tian et al., 2012; Fucik, 2010; Mirzaei and Das, 2007; Hanspal and Das, 2012; Das and Mirzaei, 2013; Mirzaei and Das, 2013; Hanspal et al., 2013) to take into account dynamic capillary pressure effect and, therefore, a detailed discussion on dynamic capillary pressure effect is avoided in this paper.

\subsection{Computational Domain}

317 Our simulation parameters are based on Bunter Sandstone Aquifer in North German Basin in 318 North-Eastern Germany. This aquifer consists of four cycles beginning with basal sandstone which has three cycles of permeable layers (Detfurth, Hardegsen and Solling-Folge) and ending 
with an alternating succession of silt, sand and clay stone (May et al., 2004). In this research study we focus on Detfurth cycle which is divided to a lower sandstone with high permeability and upper alternating succession of sand, silt and clay stones which is called (Wechselfolgen) with low permeability because it demonstrates heterogeneity in regards to porosity and permeability.

The simulated three-dimensional cylindrical domain extends laterally (r-direction) from the injection point which is represented by the well radius of 0.2 to $2500 \mathrm{~m}$ and vertically from 2900 to $3000 \mathrm{~m}$ below land surface while at the top and bottom are impermeable layers that preserve the injected $\mathrm{CO}_{2}$ safely in the storage formation. This depth ensures that the injected $\mathrm{CO}_{2}$ will remain in supercritical state which increases the storage capacity of the site. The system can be modelled as a two-dimensional radial domain, as there is no heterogeneity in the azimuthal direction. The field is segregated into $71 \times 4 \times 10$ grids cells. This grid refinement was optimized for less computational time and accurate outputs through a series of experiments that showed no significant effect of the grid refinement up to a magnitude of 10 times on the produced $\mathrm{CO}_{2}$ saturation contours. It is a fact that fine block grids produce smoother contours, however noticeable reduction of execution time was observed by using coarser grids with no momentous influence on the smoothness of $\mathrm{CO}_{2}$ profiles. This is consistent with studies by GonzalezNicolas et al. (2011) and Hanspal and Das (2012) which indicate that grid refinement has no significant influence on $P_{c}-S_{w}$ profiles.

Supercritical $\mathrm{CO}_{2}$ is to be injected at pressure and temperature above $\mathrm{CO}_{2}$ critical conditions into the centre of the computational domain at the lower $30 \mathrm{~m}$ at a constant rate of $40 \mathrm{Kg} / \mathrm{s}$ for 20 years followed by 980 years lockup period as illustrated in Figure 1 . This injection rate represents about $25 \%$ of a medium size coal-fired power generation plant. Different types of heterogeneities have been considered for the domain and various scenarios of injection process are applied to investigate the effects of permeability, temperature, porosity, and injection pressure on capillary pressure $\left(P_{c}\right)$-saturation $\left(S_{w}\right)$ relationships at static and dynamic flow conditions which has a significant influence on the fate of $\mathrm{CO}_{2}$ after the injection process.

Firstly, we run our simulations on fine and course homogenous domains with porosity of 0.16 and 0.25 , respectively, to determine the effect of porosity and permeability on $P_{c}-S_{w}$ relationships. Unlike other works (Mirzaei and Das, 2007; Peszynska and Yi, 2008; Hsu and Hilpert, 2011), dynamic and quasi-static simulations are conducted for comparison purposes. The simulated aquifer and simulation parameters are illustrated in details in Tables 1 and 2, respectively. 
In spite of considering three-dimensional flow in a permeable media, it is noted by Domenico and Schwartz (2000) that under the same hydraulic gradient, horizontal flow is of the order of six orders of magnitude faster than vertical flow. In our simulation the lateral flow dominates, therefore we can refine our computational domain by declaring our reference nodes in the output control card in the input file, vertically at distances from the bottom of the formation at 20 , 40 and $70 \mathrm{~m}$ while horizontally at radial distances of $100,200,500,800$, and $1000 \mathrm{~m}$, from the injection well while azimuthally a single reference plane is considered at $45^{\circ}$ to measure our simulation variables for two-dimensional scenarios.

\section{Results and Discussions}

To evaluate the behaviour of $\mathrm{CO}_{2}$ in three-dimensional cylindrical field-scale formation a medium-term of 1000 years of simulations of $\mathrm{CO}_{2}$ injection into homogeneous and heterogeneous formations were carried out in this work. The injection process continued for 20 years followed by 980 years of lockup. Supercritical $\mathrm{CO}_{2}$ is injected azimuthally at 4 nodes which are uniformly distributed towards the lower $30 \mathrm{~m}$ of the domain.

As stated earlier, this study aims to examine the effects of injection pressure, temperature, heterogeneities (layering), porosity, permeability and injection condition states on the $P_{c}-S_{w}$ relationships and the behaviour of the injected $\mathrm{CO}_{2}$ in terms of its dissolution or mobility. To show how $\mathrm{CO}_{2}$ behaves over the simulation time period, a series of numerical simulation models displayed in Table 3 were created for different initial and boundary conditions shown in Table 4.

\section{1. $\mathrm{CO}_{2}$ Migration}

As soon as the injection process starts the supercritical $\mathrm{CO}_{2}$ displaces the existing brine and migrates away from the injection well as illustrated in Figure 2. For different time levels, the simulated $\mathrm{CO}_{2}$ spatial distribution profiles are shown for drainage process (Figure 2 (A-D)) during the injection period and imbibition process (Figure $2(E-H)$ ) presenting the post injection period for case 1 simulation conditions (Table 3). $\mathrm{CO}_{2}$ continues to migrate laterally due to the governing forces, e.g., (i) hydrostatic pressure difference between the injection point and aquifer, and (ii) capillary pressure. Furthermore, as a result of densities difference between the ambient brine and injected supercritical $\mathrm{CO}_{2}$ buoyancy forces push the latter upwards until it reaches the impervious confining layer (caprock) under which it is trapped or extends more laterally. Figure $2(\mathrm{E}-\mathrm{H})$ demonstrates that when injection process ends the domain is invaded by brine which displaces most of the $\mathrm{CO}_{2}$ leaving part of it trapped in small pores. This leads to residual trapping of the injected $\mathrm{CO}_{2}$. Meanwhile a volume fraction of the injected $\mathrm{CO}_{2}$ are dissolved in 
the brine after the injection process to produce a rich $\mathrm{CO}_{2}$ layer that settles permanently at the bottom of the domain.

\subsection{Effects of Porosity and Permeability}

It has been suggested by some researches (e.g., Kumar et al., 2005; Xu et al., 2006; Kopp et al., 2009; Chasset et al., 2011) that an increase in the mean permeability results in greater injectivity and mobility of $\mathrm{CO}_{2}$ which increases dissolution into the formation brine. To explore this further and, in particular, determine the effects of porosity and permeability on the injectivity of $\mathrm{CO}_{2}$, two sets of simulations were carried out in this study. The first set in cases 1 and 2 explores these effects in fine and coarse homogeneous domains, respectively. The second set (cases 7 and 8) looks at the effects of two heterogeneous porous layers involving fine-coarsefine and coarse-fine-coarse layers. In all injection cases illustrated in Figure 3 , it is observed that the coarse domain produces larger $\mathrm{CO}_{2}$ plumes during the injection time at middle altitudes of the domain. This means that the higher the permeability the higher the $\mathrm{CO}_{2}$ saturation is during the drainage process when the hydrostatic forces dominate. Different plumes are produced during the imbibition process when the aquifer brine reverses back to displace the $\mathrm{CO}_{2}$. Though the $\mathrm{CO}_{2}$ plume size looks larger for the fine sand domain (Figure $3(\mathrm{~B}, \mathrm{C}, \mathrm{D})$ ) the actual sequestration of $\mathrm{CO}_{2}$ was still higher because by then a considerable amount of injected $\mathrm{CO}_{2}$ had dissolved in the existing brine and most of it would have settled at the top of the domain. This is clearly displayed in the coarse domain contours illustrated in Figure $3(G, H)$.

$\mathrm{CO}_{2}$ distribution profiles in Figure 4 demonstrates a different behaviour of the injected $\mathrm{CO}_{2}$ in fine domain where $\mathrm{CO}_{2}$ residual saturation was never reached though some tendency was noticed at a radial distance of $1000 \mathrm{~m}$ after 800 years of simulation compared to the coarse domain where residual $\mathrm{CO}_{2}$ saturation was reached at about 200 years. In contrast, all $\mathrm{CO}_{2}$ profiles in the coarse domain reach the $\mathrm{CO}_{2}$ residual saturation levels after 200 years. This is because lower permeability porous media limits both lateral and vertical $\mathrm{CO}_{2}$ mobility and maintain more contact with the surrounding brine which enhances the solubility trapping to keep the injected gas more securely within the aquifer. In addition, the small size pores in the fine domain play like meniscus tubes which allow $\mathrm{CO}_{2}$ to break through due to capillary forces to enhance residual trapping. These results are consistent with those obtained by Nordbotten et al. (2005) and Kumar et al. (2005). In the case of heterogeneity these profile show completely different trends which will be discussed in more details in section 3.6.

\subsection{Effects of Injectivity}

Capillarity plays an important role in sequestering $\mathrm{CO}_{2}$ in geological formations because it enhances the residual trapping (one of the means of sequestration). To investigate the effect of 
injection pressure on capillarity in the domain, supercritical $\mathrm{CO}_{2}$ was injected into a coarse sand domain at 36, 34 and $32 \mathrm{MPa}$ (cases 2, 5 and 6), respectively, under dynamic flow conditions. The results presented in Figure 5(A) show no significant influence of the injection pressure on capillary pressure at all saturation values which is most likely due to the employed values of injection pressure being very close to the hydrostatic pressure in the aquifer, in fact in case 6 the same value of $32 \mathrm{MPa}$ was used in addition to the high permeability of the domain which offers easier migration of $\mathrm{CO}_{2}$ laterally and vertically. These results are qualitatively consistent with the experimental results achieved by Plug and Brunning (2007).

The influence of injection pressure on $\mathrm{CO}_{2}$ saturation profiles is displayed in Figure $5(\mathrm{~B})$, which shows a steep increase in $\mathrm{CO}_{2}$ saturation at $70 \mathrm{~m}$ altitude for all injection pressures as a result of gravity forces which cause most of the injected $\mathrm{CO}_{2}$ to migrate up towards the top of the aquifer. This increase reaches the highest value at 200 years when the trends sharply steep down till they reach $\mathrm{CO}_{2}$ residual saturation. The results indicate that the higher the injection pressure, the larger the amount of $\mathrm{CO}_{2}$ accumulated at the top of the aquifer at times between $200-500$ years of simulation. This amount of $\mathrm{CO}_{2}$ is unlikely subject to any permanent trapping in short-term periods of simulation because it is not affected by the imbibition process.

\subsection{Temperature Effects on $\mathrm{CO}_{2}$ Distribution}

In this research work we inspected the effects of temperature on $\mathrm{CO}_{2}$ distribution during drainage and imbibition processes. $\mathrm{CO}_{2}$ saturation contours in Figure 6 demonstrate smaller plumes of supercritical $\mathrm{CO}_{2}$ after 20 years of injection (i.e. end of drainage process) and 200 years (during imbibition process) at a domain temperature of $80^{\circ} \mathrm{C}$ (case 5) compared to those for $58^{\circ} \mathrm{C}$ (case 3 ) under the same injection pressure conditions. This is because increasing the temperature decreases the density and viscosity of the injected $\mathrm{CO}_{2}$ and consequently increases buoyancy and gravity forces that contribute in spreading $\mathrm{CO}_{2}$ laterally and vertically. The effect of temperature on $\mathrm{CO}_{2}$ dissolution in the hosted brine is illustrated in Figure 7 . It shows that after about 200 years of simulation higher temperature results in more $\mathrm{CO}_{2}$ dissolved because it decreases $\mathrm{CO}_{2}$ density which migrates upwards to get in contact with more fresh brine which enhances the solubility trapping mechanism. Moreover it is observed in Figure 8 that capillary pressure increases proportionally with temperature and this change is more prominent between saturation values of $0.55-0.7$. The results in Figure 8 demonstrate that about $50 \%$ increase in capillary pressure is obtained when the temperature is increased from $58^{\circ} \mathrm{C}$ to $80^{\circ} \mathrm{C}$. This increase in capillary pressure permits more $\mathrm{CO}_{2}$ flow into the small pores and trap there as a residual solute, which is referred to as residual trapping of $\mathrm{CO}_{2}$. 


\subsection{Dynamic Capillary Pressure Effects}

467 Our investigations explain that in addition to the saturation, capillary pressure is strongly 468 influenced by the flow conditions in the system. Several simulation tests were carried out to compare the $\mathrm{CO}_{2}$ saturation change in homogeneous and heterogeneous computational domains under quasi-static and dynamic conditions. The results are illustrated in Figure 9 which demonstrates that higher $\mathrm{CO}_{2}$ saturation is obtained under quasi-static flow conditions at any radial distance from the injection well at all time levels. The elapsed time to attain static conditions allows more $\mathrm{CO}_{2}$ into small pores by capillary forces and it may increase convective mixing between the two fluids which enhances solubility trapping of the injected $\mathrm{CO}_{2}$. Additionally, it is noticed from Figure 10 that at saturation values above 0.55 higher capillary pressures are generated in fine-grained domain which is consistent to the theories which relate capillary pressure directly to the pore size.

To determine the dynamic or damping coefficient $(\tau)$, which indicates the extent of dynamic capillary pressure effect, two numerical simulations (cases 2 and 10) were run under dynamic and quasi-static condition, respectively. All calculation results are displayed in Figure 11. From equation (16) we calculated the dynamic coefficient for each average value of the aqueous saturation calculated by equation (14), the corresponding average values of dynamic and static capillary pressures $\left(P_{\mathrm{c}, \mathrm{dyn}}, P_{\mathrm{c}, \mathrm{stat}}\right)$, and the calculated values of the time derivative of saturation $(\partial S / \partial t)$. Figure 11 shows that the value of dynamic coefficient decreases when the rate of change of aqueous saturation increases and this decline is very sharp at low saturation values when the rate of change in aqueous saturation is slow (i.e. lower values of $\partial \mathrm{S} / \partial \mathrm{t}$ ). The attained relationship between the dynamic coefficient and aqueous saturation can be clarified by the longer time required to attain the residual saturation at higher values of dynamic coefficient.

\subsection{Effects of Heterogeneity}

492

Heterogeneity is closely related to the disparity in permeability which strongly rules the $\mathrm{CO}_{2}$ transport through different parts of the domain. To investigate this influence we compare four study cases (1, 2, 7 and 8) in terms of $\mathrm{CO}_{2}$ saturation distribution in homogenous and heterogeneous domains. As expected, and in agreement with previous studies (e.g., AtaieAshtiani et al., 2001; Das et al., 2006), heterogeneity has shown an important influence on the characteristics of two-phase flow. It is shown in Figure 12 that all trends behave similarly at 200 $\mathrm{m}$ and $40 \mathrm{~m}$ horizontal and vertical distances, respectively, as they display an increase in the integrated aqueous $\mathrm{CO}_{2}$ upon injection stops and tend to plateau after about 200 years except in case 8 (coarse sand embedded in fine) which starts to drop after 50 years of simulation. This behaviour is related to the injection section into which the supercritical $\mathrm{CO}_{2}$ was injected (lower $30 \mathrm{~m}$ ) which for this case is a fine layer bounded by a coarse one above. This scenario 
encourages vertical migration of $\mathrm{CO}_{2}$ due to the lower entry pressure of the upper strata which consequently reduces both residual and solubility trapping by eliminating the contact time between $\mathrm{CO}_{2}$ and existing brine. However, larger amount of $\mathrm{CO}_{2}$ was dissolved in the homogenous coarse domain due to the high permeability which increases $\mathrm{CO}_{2}$ movement in both directions maintaining more contact with fresh brine in which it dissolves. Figure 13 presents the total integrated amount of $\mathrm{CO}_{2}$ in aqueous and gas phases at the same grid block described above. It is apparent that all curves decline and tend to plateau soon after the injection stops except case 8 which shows sharp increase in total integrated $\mathrm{CO}_{2}$ till about 50 years of simulation and continuously increases until the end of 1000 years of simulation. This can be explained by the fact that the injected $\mathrm{CO}_{2}$ favourably move through large size pores which increases the hydrodynamic trapping as a result of pressure difference forces and $\mathrm{CO}_{2}$ concentration. This is combined with the solubility trapping due to the convective mixing of $\mathrm{CO}_{2}$ and the surrounding brine. Residual trapping is larger in the surrounded fine layer which slows down the migration of the injected $\mathrm{CO}_{2}$ providing more chance to enter the small pores.

$\mathrm{CO}_{2}$ spatial spread is demonstrated in three-dimensional cylindrical contours in Figure 14, which demonstrates how the injected supercritical $\mathrm{CO}_{2}$ spreads through different heterogeneous domains (cases 7 and 8) at different time steps. During a drainage process period of 20 years for case 7 (coarse sand embedded in fine), higher $\mathrm{CO}_{2}$ saturation values were obtained. This increase is a result of the pressure difference forces that control the lateral migration of $\mathrm{CO}_{2}$ and vertically due to the buoyancy forces that transfer the supercritical fluid from the low permeability layer up to the higher permeability one as evidently shown in Figures 14(A-D).

In contrast during imbibition process (post injection) which is presented in case 8, higher concentrations of $\mathrm{CO}_{2}$ were achieved as shown in Figures $14(\mathrm{E}, \mathrm{H})$ because in this case advective, diffusive and gravity forces all contribute in trapping the injected $\mathrm{CO}_{2}$ in addition to the reversed-back movement of the brine behind the $\mathrm{CO}_{2}$ plume to displace the $\mathrm{CO}_{2}$ again leaving traces of it as residual contaminants in small-sized pores which is referred to as residual trapping. Moreover the low permeability layer retains more contact time between the two fluids which enhances the solubility trapping mechanism. The results of this work are consistent with those obtained by Nordbotten et al. (2005) as they found out that the buoyancy forces places the highest mobility layer of injected $\mathrm{CO}_{2}$ at the top of the domain considering that in their case the $\mathrm{CO}_{2}$ was injected along the whole altitude of the domain. 


\section{Conclusion}

A series of numerical simulations have been conducted in this work to identify the possible implications of a number of important parameters on the capillary pressure - saturation relationship for supercritical $\mathrm{CO}_{2}$ in deep saline aquifer. From the results of this work it is obvious that the higher the injection pressure, the higher the capillary forces are; however, the maximum sustainable pressure has to be taken into consideration to avoid any geochemical fracture to the formation rock. The value of the dynamic coefficient $(\tau)$ increases as the rate of change of aqueous saturation ( $\partial S / \partial t)$ declines because more time is required for the residual saturation to be attained. It has been found that capillary forces are higher in fine-grained domains and they enhance storage capacity of the site by amplifying the residual trapping mechanism of $\mathrm{CO}_{2}$ during the imbibitions process. Solubility trapping is more efficient in fine domains because they maintain more contact between the fluid phases which leads to more $\mathrm{CO}_{2}$ dissolved in aquifer brine. Warm aquifers are more competent in $\mathrm{CO}_{2}$ sequestration because higher temperatures increase the capillary pressure and consequently enhance residual trapping of $\mathrm{CO}_{2}$. Fine sand embedded in coarse pattern of heterogeneity is found to be more effective method over long periods of storage procedure however more research is required to clarify how the field distribution of heterogeneity and injection scenarios of $\mathrm{CO}_{2}$ affect the efficiency of the sequestration.

\section{Acknowledgments}

We thank Dr Mark D. White from Pacific Northwest National Laboratory (PNNL), USA, for his insights and helpful comments in employing the STOMP simulation code in this study.

\section{References}

1. Alkan, H., Y. Cinar and E.B Ülker. Impact of Capillary Pressure, Salinity and In situ Conditions on $\mathrm{CO}_{2}$ Injection into Saline Aquifers. Transp. Porous Media, 2010; 84(3), 799819.

2. Anderson G.M., and D.A. Crerar. Thermodynamics in Geochemistry: The Equilibrium Model, Oxford University Press, 1992.

3. Ataie-Ashtiani, B., S.M. Hassanizadeh, M. Oostrom, M. A. Celia and M. D. White. Effective parameters for two-phase flow in a porous medium with periodic heterogeneities. Journal of Contaminant Hydrology, 2001; 49, 87-109.

4. Bachu, S., W.D. Gunter and E. H. Perkins. Aquifer disposal of $\mathrm{CO}_{2}$. Hydrodynamic and mineral trapping, Energy Conversion and Management, 1994; 35, 269-279.

5. Bachu S. and D.B. Bennion. Experimental assessment of brine and/or $\mathrm{CO}_{2}$ leakage through well cements at reservoir conditions," International Journal of Greenhouse Gas Control, 2008; 3: 494-501. 
6. Battistelli A., C. Claudio, and K. Pruess. The simulator TOUGH2/EWASG for modelling geothermal reservoirs with brines and gas. Geothermics, 1997; 26(4): 437-464.

7. Bear J. and A. Verruijt. Modelling Groundwater Flow and Pollution. D. Reidel Publishers Company, Dordrecht, the Netherlands. 1987; 414pp.

8. Beliaev, A.Y., R.J. Schotting. Analysis of a new model for unsaturated flow in porous media including hysteresis and dynamic effects. Computational Geosciences, 2002; 5, 345-368.

9. Beni A.N., M. Kühn, R. Meyer and C. Clauser. Numerical Modeling of a Potential Geological $\mathrm{CO}_{2}$ Sequestration Site at Minden (Germany). Environmental Modeling \& Assessment, August, 2012; Volume 17, Issue 4, pp 337-351.

10. Bennion D.B. and S. Bachu. Drainage and imbibition relative permeability relationships for supercritical $\mathrm{CO}_{2}$ /brine and $\mathrm{H} 2 \mathrm{~S} /$ brine systems in intergranular sandstone, carbonate, shale and anhydrite rocks. SPE. Res.Eval.\& Eng. , 2008; 11, 487-96.

11. Bickle M., A. Chadwick, H. E. Huppert, M. Hallworth and S. Lyle. Modelling carbon dioxide accumulation at Sleipner: Implications for underground carbon storage. Earth and planetary science letters, (2007); 255(1), 164-176.

12. Birkholzer J.T., Q. Zhou and C. F. Tsang. Large-scale impact of $\mathrm{CO}_{2}$ storage in deep saline aquifers: a sensitivity study on the pressure response in stratified systems. Int. J. Greenhouse Gas Control, 2009; 3(2), 181-194.

13. Bottero S., S.M. Hassanizadeh, P. J. Kleingeld and A. Bezuijen. Experimental study of dynamic capillary pressure effect in two-phase flow in porous media. In: Proceedings of the XVI International Conference on Computational Methods in Water Resources (CMWR), Copenhagen, Denmark, 2006.

14. Brooks A. and A.T. Corey. Hydraulic Properties of Porous Media. Colorado State University Hydrology, 1964; Paper No.3, Fort Collins, Colorado, U.S.A.

15. Burdine, N.T. Relative permeability calculations from pore-size distribution data. Petroleum Trans., 1953; 198:71-77.

16. Chasset C., J. Jarsjö, M. Erlström, V. Cvetkovic, G. Destouni. Scenario simulations of $\mathrm{CO}_{2}$ injection feasibility, plume migration and storage in a saline aquifer, Scania, Sweden. International Journal of Greenhouse Gas Control, 2011; 5, 1303-1318.

17. Collins, R.E. Flow of Fluids through Porous Material. Reinhold Publishing Corporation, New York, (1961).

18. Dahle, H.K., M.A. Celia, S.M. Hassanizadeh. Bundle-of-tubes model for calculating dynamic effects in the capillary pressure-saturation relationship. Transport in Porous Media, 2005; 58 (1-2), 5-22. 
19. Das, DB and Mirzaei, M (2013). Experimental measurement of dynamic effect in capillary pressure relationship for two-phase flow in weakly layered porous media, AlChE Journal, 59(5), pp.1723-1734, ISSN: 0001-1541. DOI: 10.1002/aic.13925.

20. Das, D.B., M. Mirzaei, N. Widdows. Non-uniqueness in capillary pressure-saturationrelative permeability relationships for two-phase flow in porous media: interplay between intensity and distribution of random microheterogeneities. Chem. Eng. Sci. 2006; 61, 6786-6803.

21. Domenico P.A., F.W. Schwartz. Physical and chemical hydrogeology. New York: John Willey and Sons, 2000.

22. Fučík R., J. Mikyška, T. Sakaki, M. Beneš, H. Tissa. Illangasekare. Significance of dynamic effect in capillarity during drainage experiments in layered porous media. Vadose Zone J. 2010; 9:697-708.

23. Gonzalez-Nicolas A., B. Cody and D. Bau. Numerical simulation of $\mathrm{CO}_{2}$ injection into deep saline aquifers. Proceedings AGU Hydrology Days, 21-23 March 2011, accessed online on 04/04/2014 at; http://hydrologydays.colostate.edu/

24. Haas J.L. Physical Properties of the Coexisting Phases and Thermochemical Properties of the $\mathrm{H}_{2} \mathrm{O}$ Component in Boiling $\mathrm{NaCl}$ Solutions. Preliminary Steam Tables for $\mathrm{NaCl}$ Solutions. Geological Survey Bulletin, 1976; 1421-A, U.S. Department of the Interior.

25. Hanspal N.S. and D.B. Das. Dynamic Effects on Capillary Pressure-Saturation Relationships for Two-Phase Porous Flow: Implications of Temperature. AIChE Journal, 2012; Vol. 58, No. 6.

26. Hanspal, N, Allison, BA, Deka, L, Das, DB (2013) Artificial neural network (ANN) modeling of dynamic effects on two-phase flow in homogenous porous media, Journal of Hydroinformatics, 15(2), pp.540-554, DOI: 10.2166/hydro.2012.119.

27. Hanyga, A., M. Seredynska. A dynamic model of capillary hysteresis in immiscible fluid displacement. Transport in Porous Media, 2005; 59, 249-265.

28. Hassanizadeh, S.M., W.G. Gray. Thermodynamic basis of capillary pressure in porous media. Water Resources Research, 1993a; 29(10), pp.3389-3405.

29. Helmig, R. Multiphase Flow and Transport Processes in the Subsurface. Springer, Berlin, 1997; 367pp.

30. Helmig, R., A. Weiss and B.I. Wohlmuth. Dynamic Capillary Effects in Heterogeneous Porous Media. Computers \& Geosciences, 2007; 11: p. 261-274.

31. Hsu S-Y and M. Hilpert. Incorporati on of Dynamic Capillary Pressure into the GreenAmpt Model for Infiltration. Vadose Zone J. 2011; 10:642-653. Doi:10.2136/vzj2010.0069 
32. Ide S.K., K. Jessen , Jr.F.M. Orr. Storage of $\mathrm{CO}_{2}$ in saline aquifers: Effects of gravity, viscous, and capillary forces on amount and timing of trapping. International journal of greenhouse gas control, 2007; 1, 481 - 491.

33. Juanes, R., E.J. Spiteri, Jr.F.M. Orr and M.J Blunt. Impact of relative permeability hysteresis on geological $\mathrm{CO}_{2}$ storage, Water Resour. Res. 2006; 42, W12418, doi:10.1029/2005WR004806.

34. Knauss K.G., J.W. Johnson and C. I Steefel. Evaluation of the impact of $\mathrm{CO}_{2}$, cocontaminant gas, aqueous fluid and reservoir rock interactions on the geologic sequestration of $\mathrm{CO}_{2}$. Chem. Geol. 2005; 217:339-350.

35. Kopp A., H. Class, R. Helmig. Investigations on $\mathrm{CO}_{2}$ storage capacity in saline aquifers Part 1. Dimensional analysis of flow processes and reservoir characteristics. International Journal of Greenhouse Gas Control, 2009; 3: 263-276.

36. Kumar A., M. Noh, G.A. Pope, K. Sepehrnoori, S. Bryant and L. W. Lake. Reservoir Simulation of $\mathrm{CO}_{2}$ Storage in Deep Saline Aquifers. SPEJ, 2005; 10 (3): 336-348.

37. Lyle S., H.E. Huppert, M. Hallworth, M. Bickle and A. Chadwick. Axisymmetric gravity currents in a porous medium, J. Fluid Mech. 2005; 543, 293-302.

38. Manthey, S., S.M. Hassanizadeh and R. Helmig. Macro-scale dynamic effects in homogeneous and heterogeneous porous media. Transport in Porous Media, 2005; 58 (1-2), 121-145.

39. May , F., P. Krull and P. Gerling. $\mathrm{CO}_{2}$ Storage Scenarios in North Germany. GESTCO Project Case Studies. - Bundesanstalt für Geowissenschaften und Rohstoffe, 2004; 50 p.

40. Meyer, C.A., R.B. McClintock, G.J. Silvestri, and R.C. Spencer. ASME Steam Tables, The American Society of Mechanical Engineers, New York, 1993.

41. Mirzaei M. and D. B. Das. Dynamic effects in capillary pressure saturations relationships for two-phase flow in 3D porous media: implications of micro-heterogeneities. Chem Eng Sci. 2007; 62:1927-1947.

42. Mirzaei, M and Das, DB (2013) Experimental investigation of hysteretic dynamic effect in capillary pressure-saturation relationship for two-phase flow in porous media, AlChE Journal, 59, pp.3958-3978, DOI: 10.1002/aic.14121.

43. Nitao, J.J. Numerical Modeling of the Thermal and Hydrological Environment around a NuclearWaste Package Using the Equivalent Continuum Approximation: Horizontal Emplacement, 1988; UCID-2144, Lawrence Livermore National Laboratory, Livermore, California.

44. Nordbotten, J. M., M. A. Celia, S. Bachu. Analytical solutions for leakage rates through abandoned wells. Water Resources Research, 2004; 40,W04204, doi:10.1029/2003WR002997. 
45. Nordbotten J.M., M.A. Celia and S. Bachu. Injection and Storage of $\mathrm{CO}_{2}$ in Deep Saline Aquifers: Analytical Solution for $\mathrm{CO}_{2}$ Plume Evolution During Injection. Transp Porous Med (2005) 58:339-360.

46. Oung O., S.M. Hassanizadeh and A. Bezuijen. Two-phase flow experiments in a geocentrifuge and the significance of dynamic capillary pressure effect. Journal of Porous Media, 2005; 8 (3), 247-257.

47. Peszynska M., S-Y Yi. Numerical Methods for Unsaturated Flow with Dynamic Capillary Pressure in Heterogeous Porous Media. International Journal of Numerical Analysis and Modeling, 2008; Volume 5, Supp , Pages 126-149.

48. Plug W.J. and J. Bruining. Capillary pressure for the sand- $\mathrm{CO}_{2}-$ Water system under various pressure conditions. Application to $\mathrm{CO}_{2}$ sequestration. Advances in Water Resources, 2007; 30- 2339 -2353.

49. Prausnitz J.M., R.N. Lichtenthaler and E. Gome de Azevedo. Thermodynamics of FluidPhase Equilibria. Prentice-Hall; N. J. Englewood Cliffs 1986; Chapter 6, pp 193.

50. Prevost J., R. Fuller, A.S. Altevogt, R. Bruant and G. Scherer. Numerical Modelling of Carbon Dioxide Injection and Transport in Deep Saline Aquifers. Greenhouse Gas Control Technologies, 2005; 2: 2189-2193.

51. Pruess K., T. Xu, J. Apps and J. Garcia. Numerical modeling of aquifer disposal of $\mathrm{CO}_{2}$. 2003; Paper SPE-83695. SPE J. 49-60.

52. Redlich, O., and J.N.S. Kwong, On the Thermodynamics of Solutions. V: An Equation of State. Fugacities of Gaseous Solutions. Chem. Rev. 1949; 44, 233.

53. Rowlinson, J.S. and J.D. Van der Waals: On the Continuity of the Gaseous and Liquid States, Elsevier, Amsterdam 1988.

54. Scheidegger, A.E. Physics of Flow Through Porous Media. University of Toronto Press, Toronto, 1974.

55. Schnaar G. and D.C. Digiulio. Computational Modeling of the Geologic Sequestration of Carbon Dioxide. Vadose Zone Journal, 2009; 8 (2): 389-403.

56. Silin D., T. Patzek, S.M. Benson. A Model of Buoyancy-Driven Two-Phase Countercurrent Fluid Flow. Transp Porous Med, 2009; 76:449-469.

57. Soave G. Equilibrium Constants from a Modified Redlich-Kwong. Equation of State, Chem. Eng. Sci. 1972; 27, 1197.

58. Span R. and W. Wagner. A new equation of state for carbon dioxide covering the fluid region from the triple-point temperature to $1100 \mathrm{~K}$ at pressures up to $800 \mathrm{MPa}$. J Phys Chem Ref Data 1996; 25:1509-1596.

59. Spycher N., K. Pruess, and J. Ennis-King. $\mathrm{CO}_{2}-\mathrm{H}_{2} \mathrm{O}$ mixtures in geological sequestration of $\mathrm{CO}_{2}$. I. Assessment and calculation of mutual solubilities from 12 to $100^{\circ} \mathrm{C}$ and up to 
600 bar. Geochimica et Cosmoschimica Acta, 2003, 67(16):3015-3031, doi:10.1016/s0016-7037(03)00273-4.

60. Spycher, N. and K. Pruess. A phase-partitioning model for $\mathrm{CO}_{2}$-brine mixtures at elevated temperatures and pressures: Application to $\mathrm{CO}_{2}$-enhanced geothermal systems. Transport in Porous Media, 2010; 82:173-196, doi:10.1007/s11242-009-9425-y.

61. Tian S., G. Leig, S. He, L. Yang. Dynamic effect of capillary pressure in low permeability reservoirs. PETROL. EXPLOR. DEVELOP., 2012, 39(3): 405-411.

62. Tsang Chin-Fu, E.J. Birkholzer, E.J. Rutqvist. A comparative review of hydrologic issues involved in geologic storage of $\mathrm{CO}_{2}$ and injection disposal of liquid waste. Environ Geol, 2008; 54:1723-1737.

63. van Genuchten, M.Th. 1980. "A closed-form equation for predicting the hydraulic conductivity of unsaturated soils." Soil Sci. Soc. Am. J., 44:892-898.

64. Wei Y.S. and R.J. Sadus. Equations of State for the Calculation of Fluid-Phase Equilibria. AIChE Journal, 2000; Vol. 46, No. 1, 169-196. doi: 10.1002/aic.690460119.

65. White, M.D. And M. Oostrom. STOMP subsurface transport over multiple phases, Version 3.0, An Introductory Short Course. 2003; PNNL 1440, Pacific Northwest National Laboratory, Richland, Washington. In Press.

66. White M.D., D. J. Watson, D. H. Bacon, S. K. White, B. P McGrail, Z. F. Zhang. STOMP Subsurface Transport Over Multiple Phases STOMP-CO 2 and $-\mathrm{CO}_{2} \mathrm{e}$ Guide, Version 1.1, September 2013; PNNL-21268, Pacific Northwest National Laboratory.

67. Xu, T., E. Sonnenthal, N. Spycher, K. Pruess. TOUGHREACT: A simulation program for non-isothermal multiphase reactive geochemical transport in variably saturated geologic media: Applications to geothermal injectivity and $\mathrm{CO}_{2}$ geological sequestration. Comput. Geosci. 2006; 32:145-165. 
Table 1. Selected aquifer parameters for simulation

\begin{tabular}{|c|c|c|c|}
\hline Parameter & \multicolumn{2}{|c|}{ Value/Function } & Reference \\
\hline Diameter (m) & \multicolumn{2}{|c|}{5000} & - \\
\hline Thickness (m) & \multicolumn{2}{|c|}{100} & - \\
\hline Depth $(m)$ & \multicolumn{2}{|c|}{2900} & - \\
\hline Grid (nodes) & \multicolumn{2}{|c|}{$71 \times 4 \times 10$} & - \\
\hline Porosity & $\begin{array}{c}\text { Sandstone } \\
0.25\end{array}$ & $\begin{array}{l}\text { (Wechselfolgen) } \\
\quad 0.16\end{array}$ & May et al. (2004) \\
\hline Horizontal Permeability $\left(\mathrm{m}^{2}\right)$ & $(5.625 e-13)$ & $(0.5428 \mathrm{e}-13)$ & May et al. (2004) \\
\hline Vertical Permeability $\left(\mathrm{m}^{2}\right)$ & $(1.688 \mathrm{e}-13)$ & $(11.15 \mathrm{e}-16)$ & May et al. (2004) \\
\hline rock density $\left(\mathrm{kg} / \mathrm{m}^{3}\right)$ & 2430 & 2470 & May et al. (2004) \\
\hline specific storativity $(1 / m)$ & \multicolumn{2}{|c|}{$9.2 \mathrm{e}-4$} & May et al. (2004) \\
\hline Surface temperature $\left({ }^{\circ} \mathrm{C}\right)$ & \multicolumn{2}{|c|}{8} & May et al. (2004) \\
\hline Reservoir temperature $\left({ }^{\circ} \mathrm{C}\right)$ & \multicolumn{2}{|c|}{58} & Beni et al. (2012) \\
\hline Temperature gradient $(\mathrm{K} / \mathrm{m})$ & \multicolumn{2}{|c|}{0.035} & Reinicki, (1968) \\
\hline Reservoir pressure (MPa) & \multicolumn{2}{|c|}{32} & Beni et al. (2012) \\
\hline Pressure gradient $(\mathrm{KPa} / \mathrm{m})$ & \multicolumn{2}{|c|}{10.5} & Beutler, (1975) \\
\hline
\end{tabular}


Table 2. Important parameters and initial conditions

\begin{tabular}{|c|c|c|}
\hline Parameter & Value & Reference \\
\hline $\begin{array}{l}\text { Irreducible saturations } \\
\text { water, } S_{\mathrm{Ir}}\end{array}$ & 0.1 & Beni et al. (2012) \\
\hline $\mathrm{CO}_{2}, \mathrm{~S}_{\mathrm{gr}}$ & 0.05 & Beni et al. (2012) \\
\hline $\begin{array}{l}\text { Brooks/Corey } \\
\text { Exponent, } \lambda\end{array}$ & 0.457 & Beni et al. (2012) \\
\hline Strength coefficient, $P_{0}$ & $19,610 \mathrm{~Pa}$ & Beni et al. (2012) \\
\hline Pore compressibility, $k$ & $1 x e^{-9} \mathrm{~Pa}^{-1}$ & Beni et al. (2012) \\
\hline Pore expansivity, $\boldsymbol{\beta}$ & $1 x e^{-6} K^{-1}$ & Beni et al. (2012) \\
\hline Injection Pressure & $36 \mathrm{MPa}$ & - \\
\hline Temperature & $58^{\circ} \mathrm{C}$ & Beni et al. (2012) \\
\hline Salinity & 0.2 & Beni et al. (2012) \\
\hline Pressure gradient & $\begin{array}{c}10.5 \\
\mathrm{MPa} / \mathrm{Km}\end{array}$ & May et al. (2004) \\
\hline Salinity gradient & $80 \mathrm{~g} / \mathrm{L} . \mathrm{Km}$ & May et al. (2004) \\
\hline $\mathrm{CO}_{2}$ injection rate & $40 \mathrm{Kg} / \mathrm{s}$ & - \\
\hline Injection time & $20 \mathrm{Yrs}$ & - \\
\hline Simulation time & 1000 Yrs & - \\
\hline
\end{tabular}


Table 3. Simulation cases and parameters

\begin{tabular}{|c|c|c|c|c|c|c|c|}
\hline Conditions & $\begin{array}{c}\text { Case } \\
\text { No. }\end{array}$ & Domain & $\begin{array}{l}\text { Inject. } \\
\text { Press. } \\
\text { (MPa) }\end{array}$ & $\underset{{ }^{\circ} \mathrm{C}}{\text { Temp. }}$ & Porosity & $\begin{array}{l}\text { Horiz. Perm. } \\
\left(\mathrm{m}^{2}\right)\end{array}$ & $\begin{array}{l}\text { Vert. Perm. } \\
\left(\mathrm{m}^{2}\right)\end{array}$ \\
\hline \multirow{8}{*}{ Dynamic } & 1 & $\begin{array}{l}\text { Homogeneous } \\
\text { (Fine) }\end{array}$ & 36 & 58 & 0.16 & $0.5428 \mathrm{e}-13$ & $0.01115 \mathrm{e}-13$ \\
\hline & 2 & \multirow{5}{*}{ 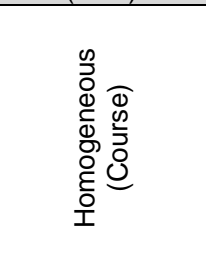 } & 36 & 58 & \multirow{5}{*}{0.25} & \multirow{5}{*}{$5.625 e-13$} & \multirow{5}{*}{$1.6876 \mathrm{e}-13$} \\
\hline & 3 & & 36 & 70 & & & \\
\hline & 4 & & 36 & 80 & & & \\
\hline & 5 & & 34 & 58 & & & \\
\hline & 6 & & 32 & 58 & & & \\
\hline & 7 & $\begin{array}{l}\text { Heterogeneous } \\
\text { fine-coarse- } \\
\text { fine }\end{array}$ & 36 & 58 & $0.16-0.25-0.16$ & Variable & Variable \\
\hline & 8 & $\begin{array}{l}\text { Heterogeneous } \\
\text { coarse-fine- } \\
\text { coarse }\end{array}$ & 36 & 58 & $0.25-.016-0.25$ & Variable & Variable \\
\hline $\begin{array}{l}\text { Quasi } \\
\text { Static }\end{array}$ & 9 & $\begin{array}{c}\text { Homogeneous } \\
\text { (Fine) }\end{array}$ & 36 & 58 & 0.16 & $0.5428 \mathrm{e}-13$ & $0.01115 e-13$ \\
\hline $\begin{array}{l}\text { Quasi } \\
\text { Static }\end{array}$ & 10 & $\begin{array}{c}\text { Homogeneous } \\
\text { (Coarse) }\end{array}$ & 36 & 58 & 0.25 & $5.625 e-13$ & $1.6876 \mathrm{e}-13$ \\
\hline
\end{tabular}


Table 4. Initial and boundary conditions

\begin{tabular}{|c|c|c|c|c|}
\hline $\begin{array}{l}\text { Case } \\
\text { No. }\end{array}$ & $\begin{array}{l}\text { Domain } \\
\text { Type/Cond. }\end{array}$ & $\begin{array}{l}\text { Horizontal } \\
\text { Permeability } \\
\left(\mathrm{m}^{2}\right)\end{array}$ & $\begin{array}{c}\text { Domain } \\
\text { Temp. } \\
\left({ }^{\circ} \mathrm{C}\right)\end{array}$ & $\begin{array}{c}\mathrm{CO}_{2} \\
\text { Injection } \\
\text { Pressure } \\
(\mathrm{MPa})\end{array}$ \\
\hline \multicolumn{5}{|c|}{ Dynamic } \\
\hline 1 & $\begin{array}{l}\text { Homogenous } \\
\text { Fine Sand }\end{array}$ & $0.5428 e-13$ & 58 & 36 \\
\hline 2 & $\begin{array}{l}\text { Homogenous } \\
\text { Coarse Sand }\end{array}$ & $5.625 e-13$ & 58 & 36 \\
\hline 3 & $\begin{array}{l}\text { Homogenous } \\
\text { Coarse Sand }\end{array}$ & $5.625 e-13$ & 70 & 36 \\
\hline 4 & $\begin{array}{l}\text { Homogenous } \\
\text { Coarse Sand }\end{array}$ & $5.625 e-13$ & 80 & 36 \\
\hline 5 & $\begin{array}{l}\text { Homogenous } \\
\text { Coarse Sand }\end{array}$ & $5.625 e-13$ & 58 & 34 \\
\hline 6 & $\begin{array}{l}\text { Homogenous } \\
\text { Coarse Sand }\end{array}$ & $5.625 e-13$ & 58 & 32 \\
\hline 7 & $\begin{array}{l}\text { Heterogeneous } \\
\text { Coarse in Fine Sand }\end{array}$ & $\begin{array}{c}0.5428 e-13-5.625 e-13- \\
0.5428 e-13\end{array}$ & 58 & 36 \\
\hline 8 & $\begin{array}{l}\text { Heterogeneous } \\
\text { Coarse in Fine Sand }\end{array}$ & $\begin{array}{c}5.625 e-13-0.5428 e-13-5.625 e- \\
13\end{array}$ & 58 & 36 \\
\hline 9 & $\begin{array}{l}\text { Quasi-Static } \\
\text { Homogenous } \\
\text { Fine Sand }\end{array}$ & $0.5428 \mathrm{e}-13$ & 58 & 36 \\
\hline 10 & $\begin{array}{l}\text { Homogenous } \\
\text { Fine Sand }\end{array}$ & $0.5428 \mathrm{e}-13$ & 58 & 36 \\
\hline 11 & $\begin{array}{l}\text { Homogenous } \\
\text { Fine Sand } \\
\end{array}$ & $0.5428 \mathrm{e}-13$ & 58 & 32 \\
\hline $\begin{array}{l}\text { Porosit) } \\
\text { Vertical } \\
\text { Hydros }\end{array}$ & $\begin{array}{lr}\text { rmeability; } & \text { Fine Sal } \\
\text { F Pressure Sar } & =32 \mathrm{MPa},\end{array}$ & $\begin{array}{l}=0.16, \quad \text { Coarse Sand }=0.25 \\
=0.01115 \mathrm{e}-13, \quad \text { Coarse Sand }=1.68 \\
\text { essure Gradient= } 10.5 \mathrm{MPa} / \mathrm{Km}, \text { Salini }\end{array}$ & $\begin{array}{l}6 e-13 \\
=0.2\end{array}$ & \\
\hline
\end{tabular}




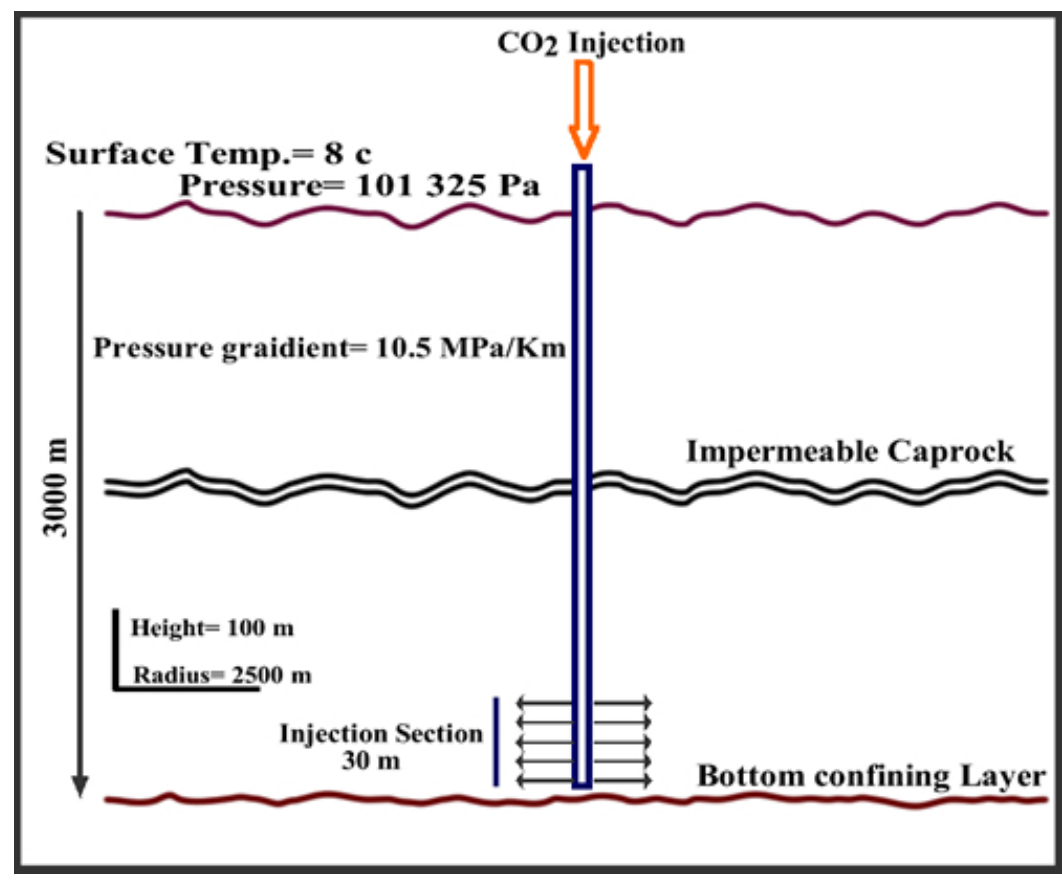

Figure 1. A schematic diagram of geological $\mathrm{CO}_{2}$ sequestration process in a deep saline aquifer (DSA). 


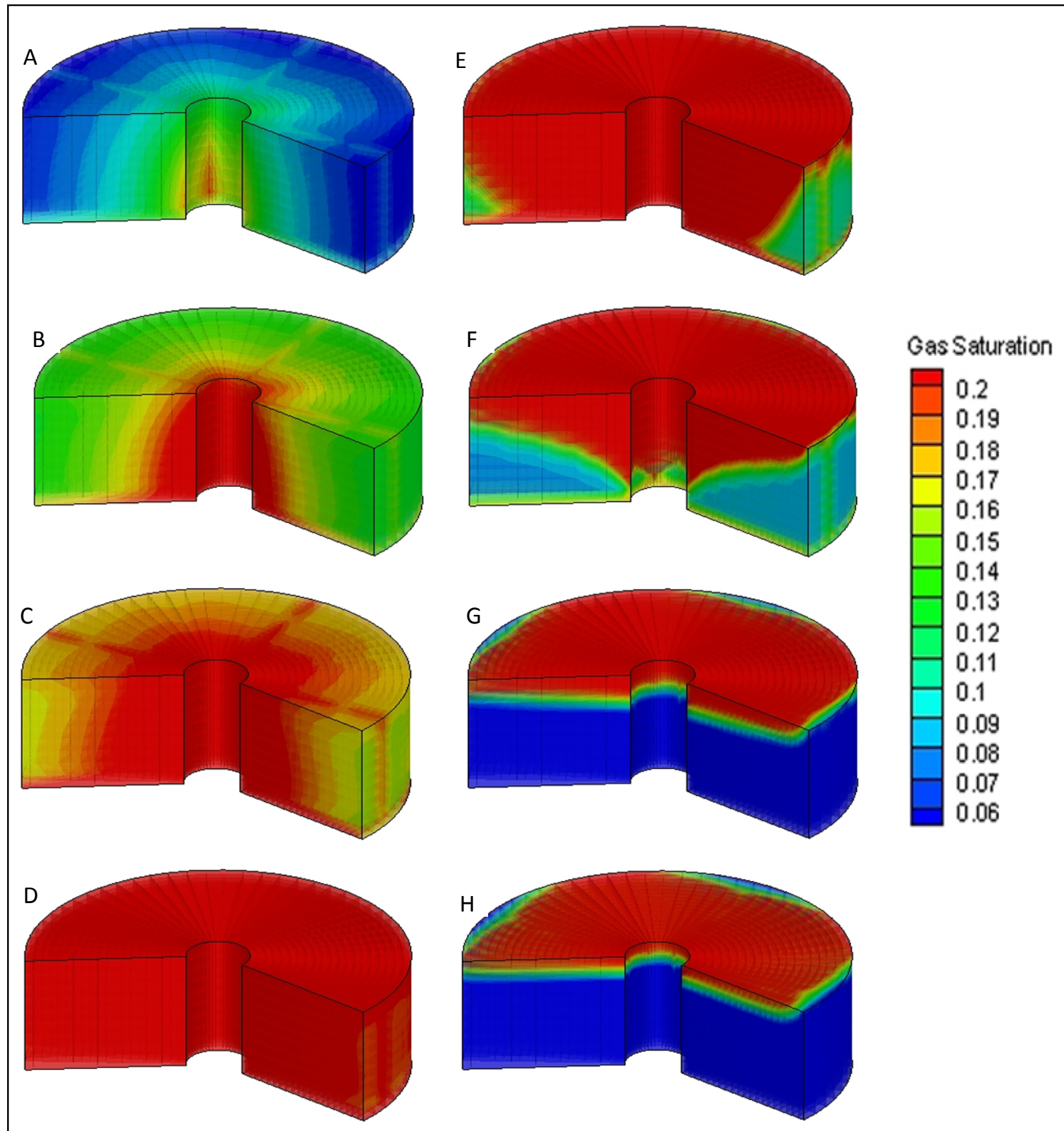

Figure 2. Evolution of $\mathrm{CO}_{2}$ plume in low permeability homogenous aquifer (case1):

(A-D) $\mathrm{CO}_{2}$ distribution after $1,5,10$ and 20 years of simulation during injection process (drainage). (E-H) $\mathrm{CO}_{2}$ distribution after $50,200,500$ and 1000 years post injection process (imbibition). 


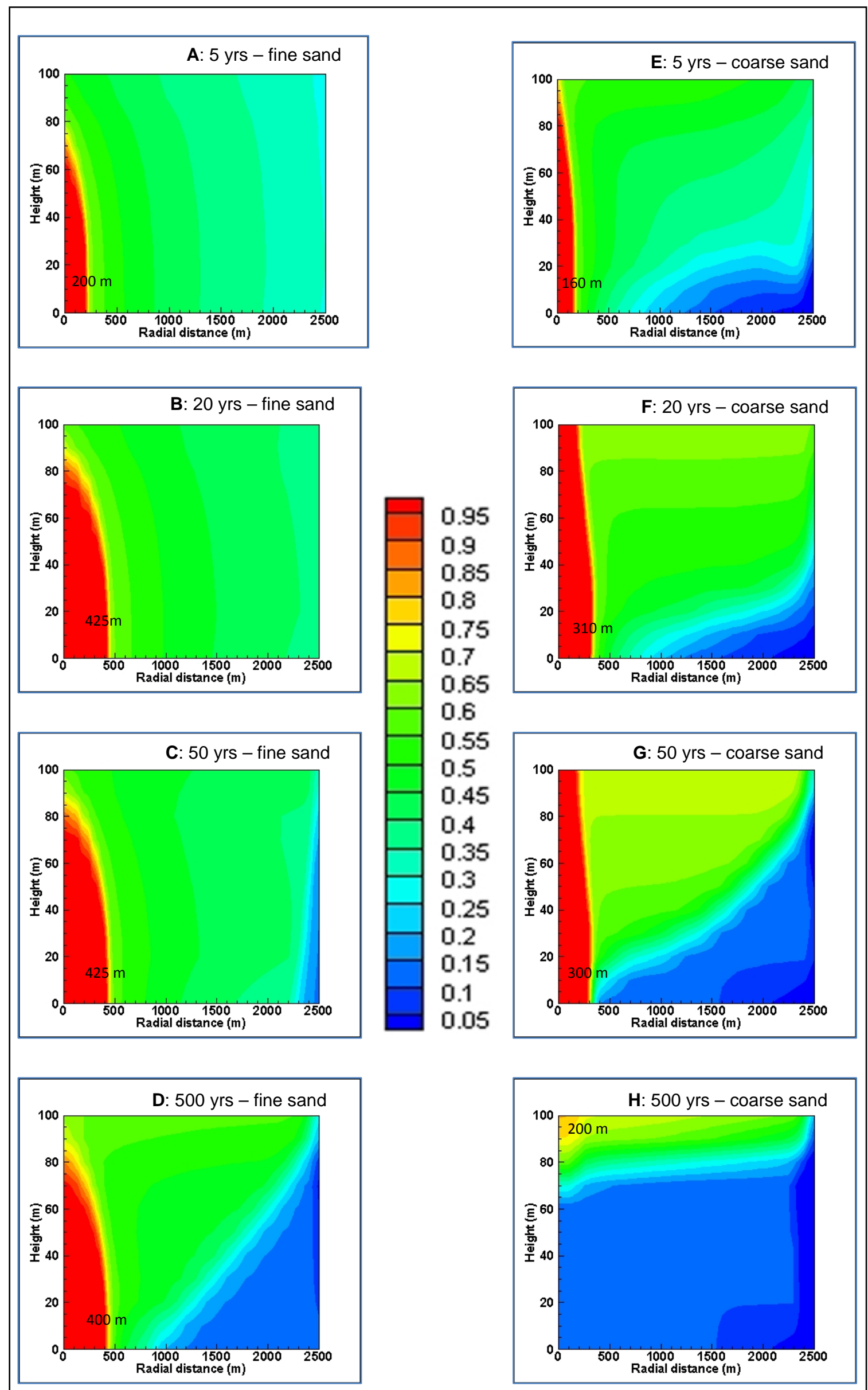

Figure 3. $\mathrm{CO}_{2}$ plume evolution in low and high permeability homogenous aquifers at different time scales; (A-D) fine sand domain (Case 1), (E-H) coarse sand domain (Case 2). 

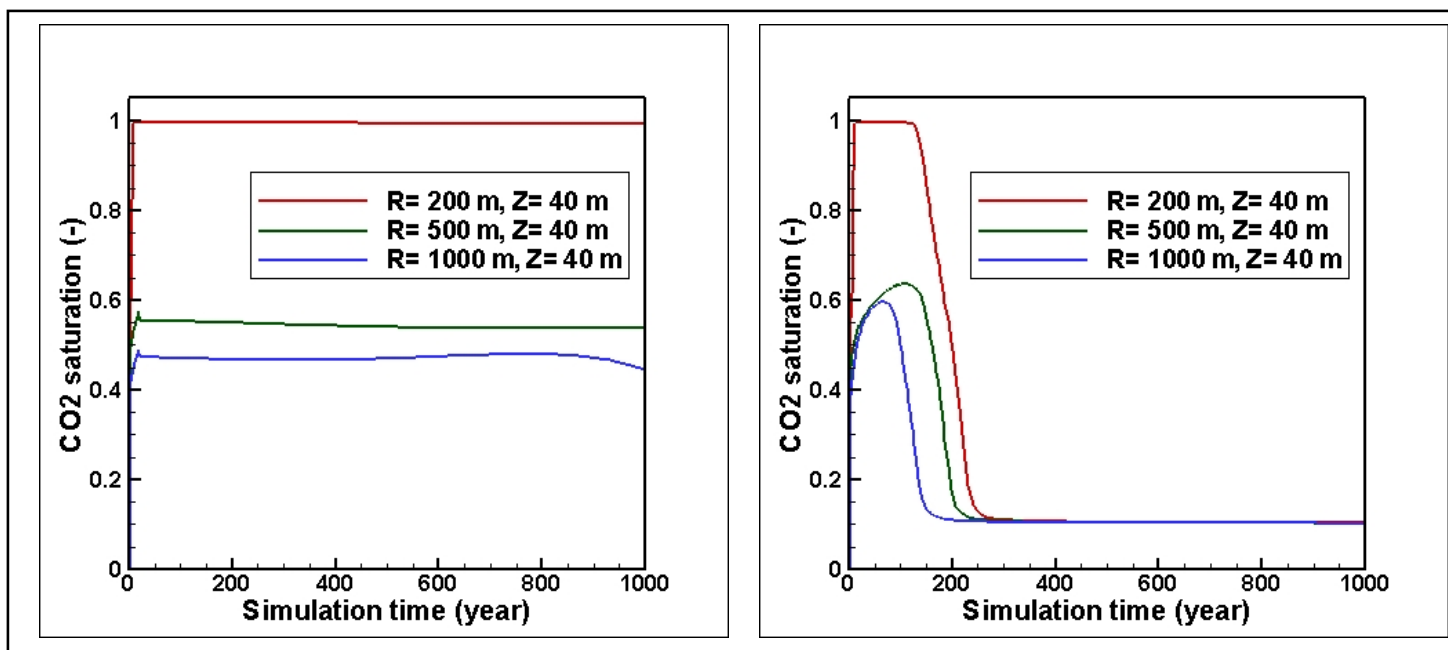

Figure 4. $\mathrm{CO}_{2}$ saturation plots for homogenous domains: Case 1 - fine sand (left) and case 2 - coarse sand (right). 

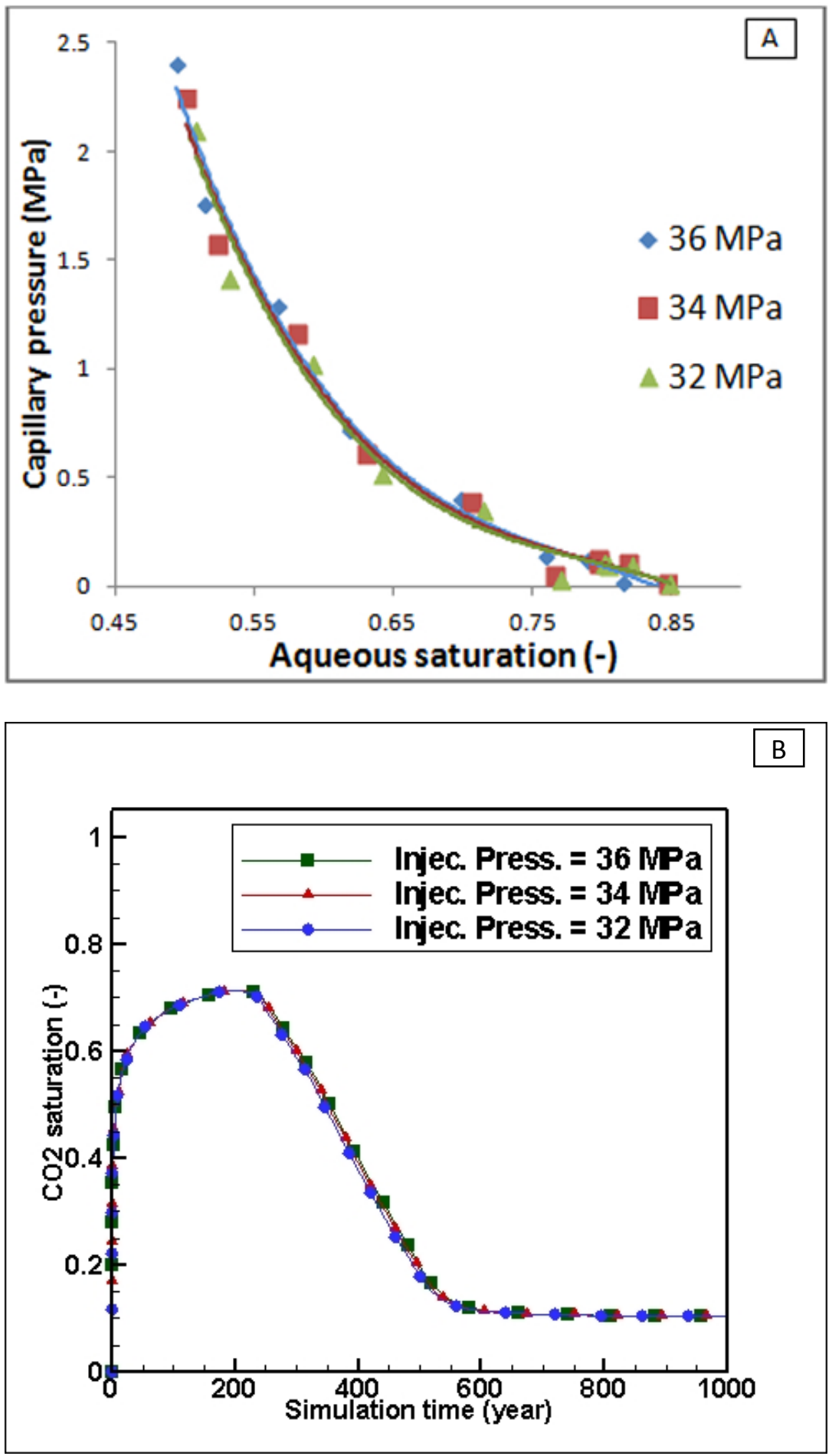

Figure 5. A- Capillary pressure vs. aqueous saturation at different injection pressures.

B- $\mathrm{CO}_{2}$ saturation curves at $\mathrm{R}=500 \mathrm{~m}$ and $\mathrm{Z}=70 \mathrm{~m}$ in a coarse homogeneous domain. 


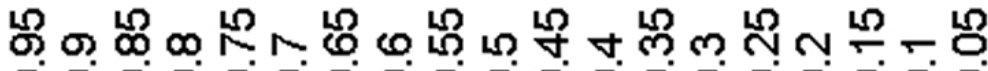 0000000000000000000}
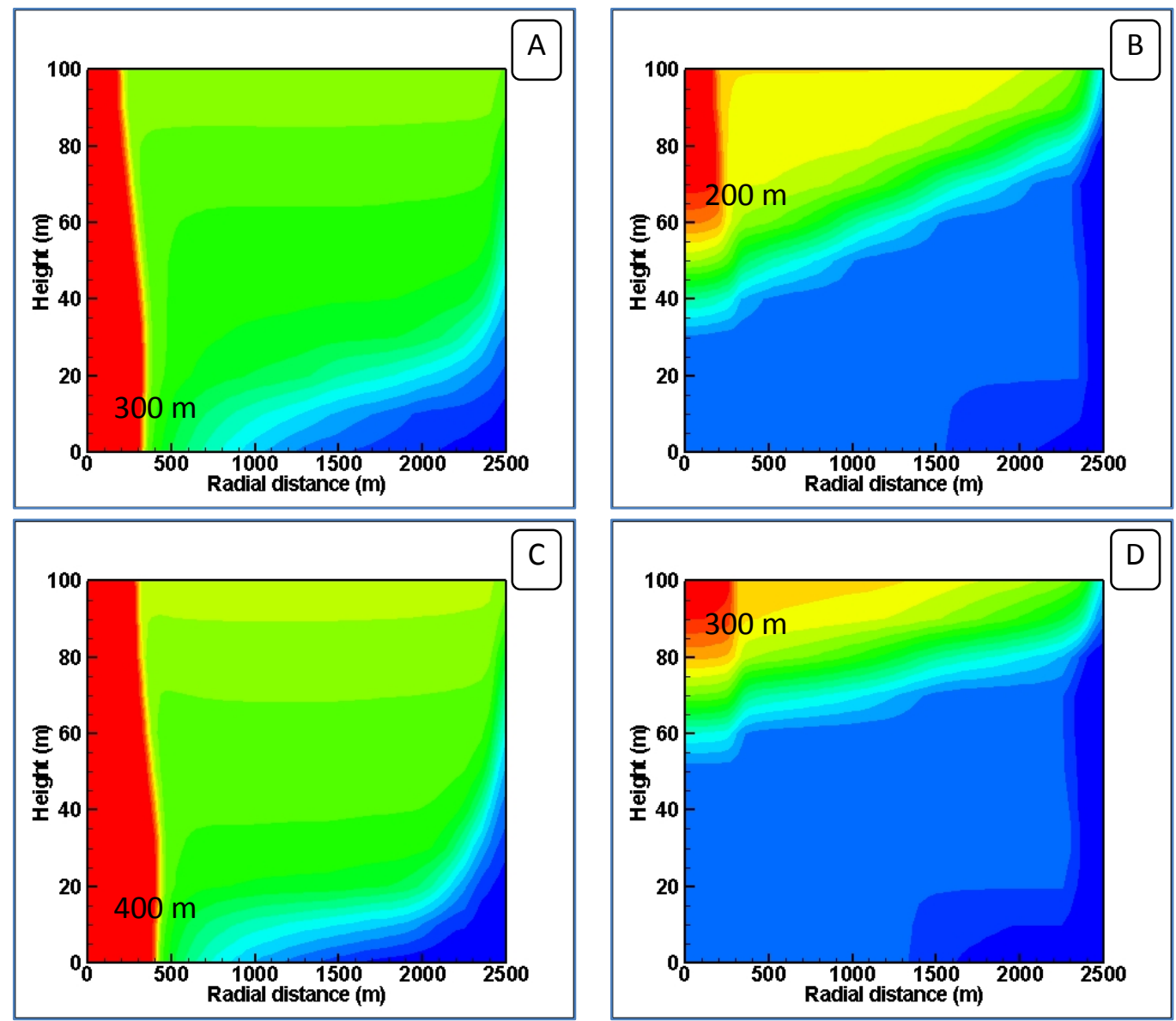

Figure 6. $\mathrm{CO}_{2}$ plume evolution in high permeability homogenous aquifer at different times and temperatures;

A- after 20 years at $58^{\circ} \mathrm{C}, \mathbf{B}$ - after 200 years at $58^{\circ} \mathrm{C}$ (Case 2)

C- after 20 years at $80^{\circ} \mathrm{C}, \mathrm{D}$ - after 200 years at $80^{\circ} \mathrm{C}$ (Case 4 ) 


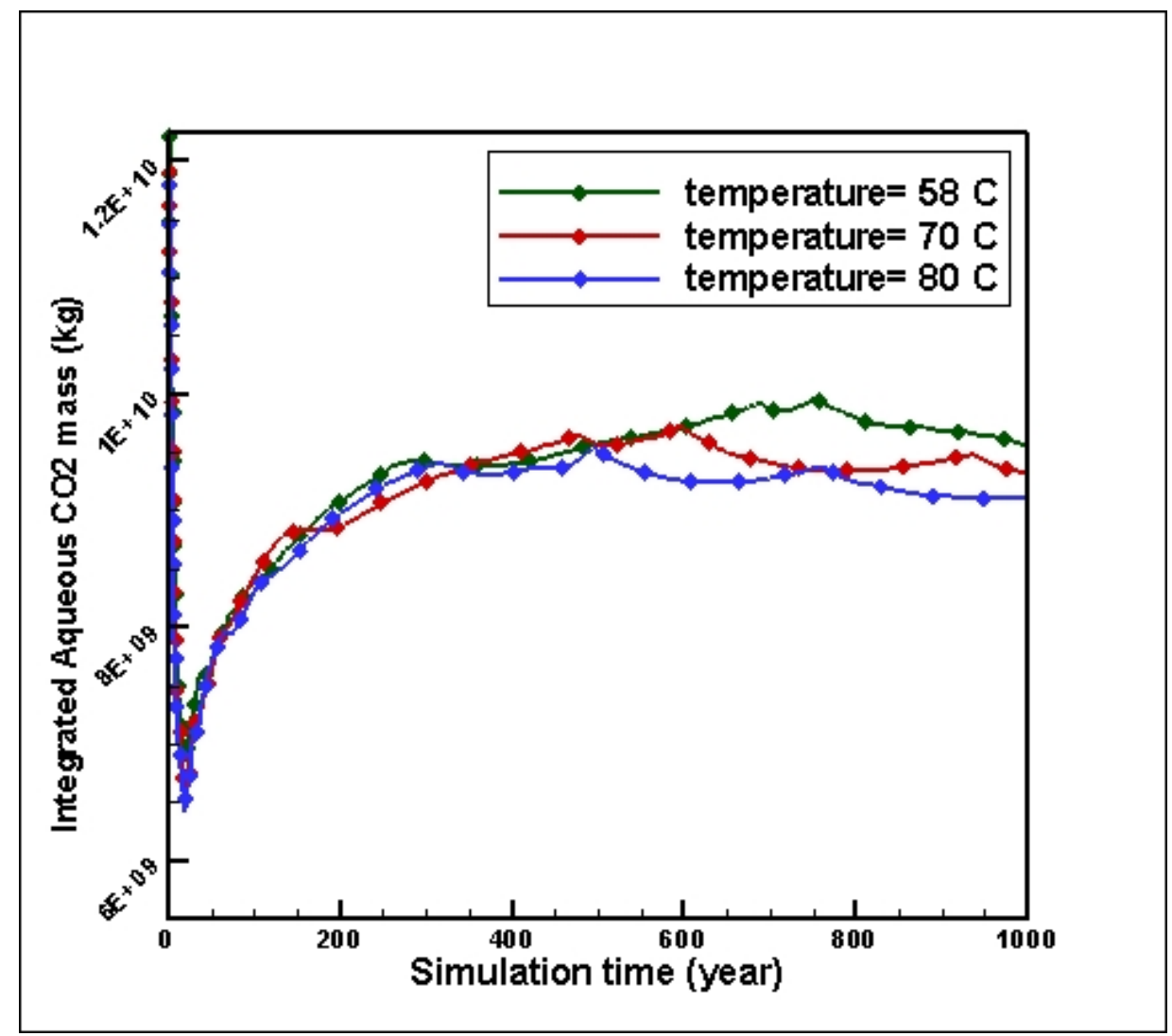

Figure 7. Temperature effects on dissolved $\mathrm{CO}_{2}$ mass (cases 2, 3 and 4). 


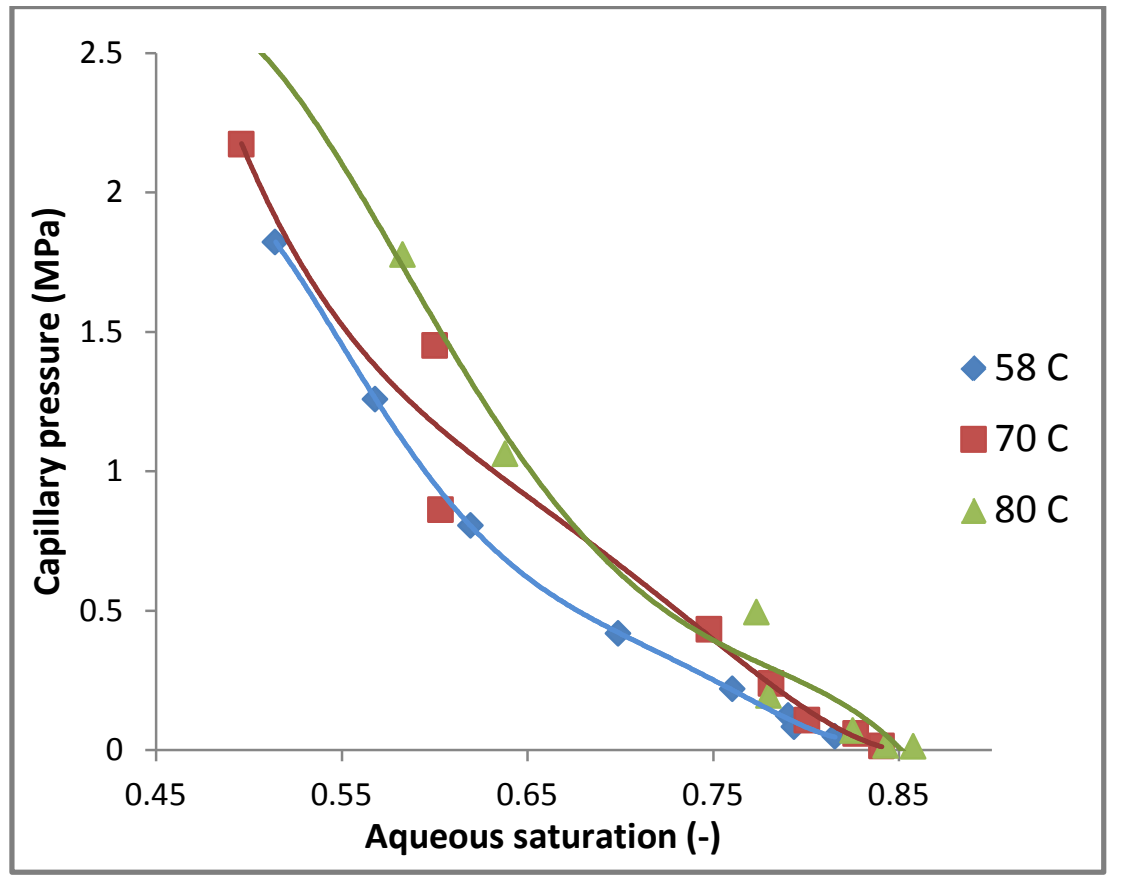

Figure 8. Capillary pressure vs. aqueous saturation at different temperatures (cases 2, 3 and 4). 


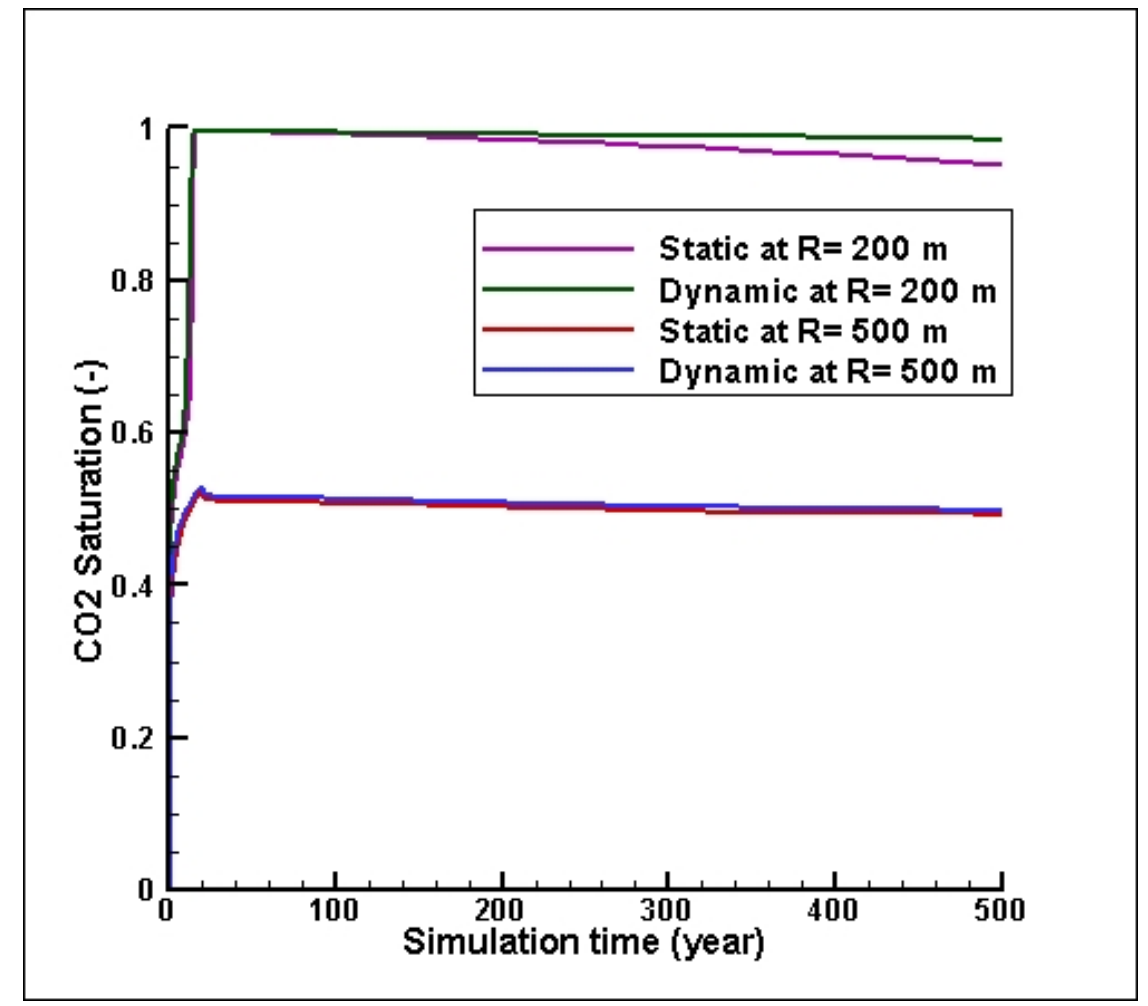

Figure 9. $\mathrm{CO}_{2}$ saturation (volume fraction) curves for homogenous fine domain under static and dynamic conditions at altitude of $40 \mathrm{~m}$ (cases 1 and 9). 


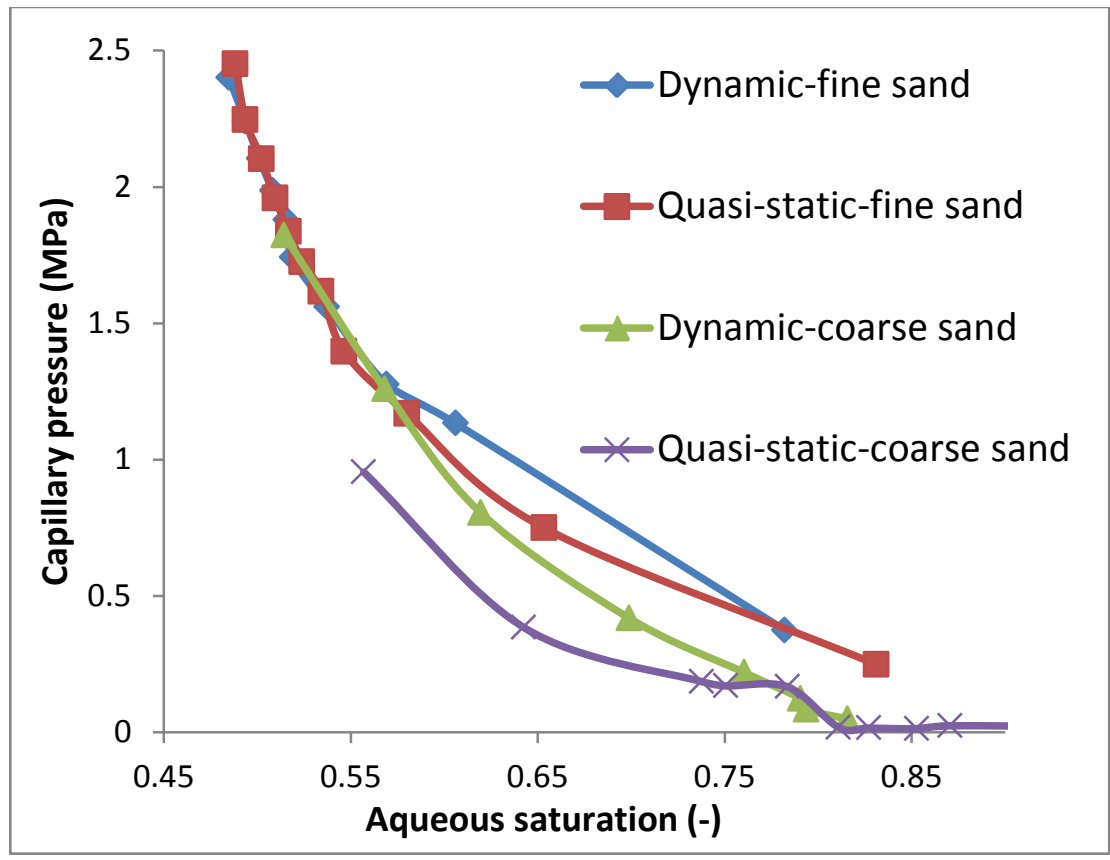

Figure 10. Dynamic and quasi-static capillary pressure-saturation curves for homogenous domains. 


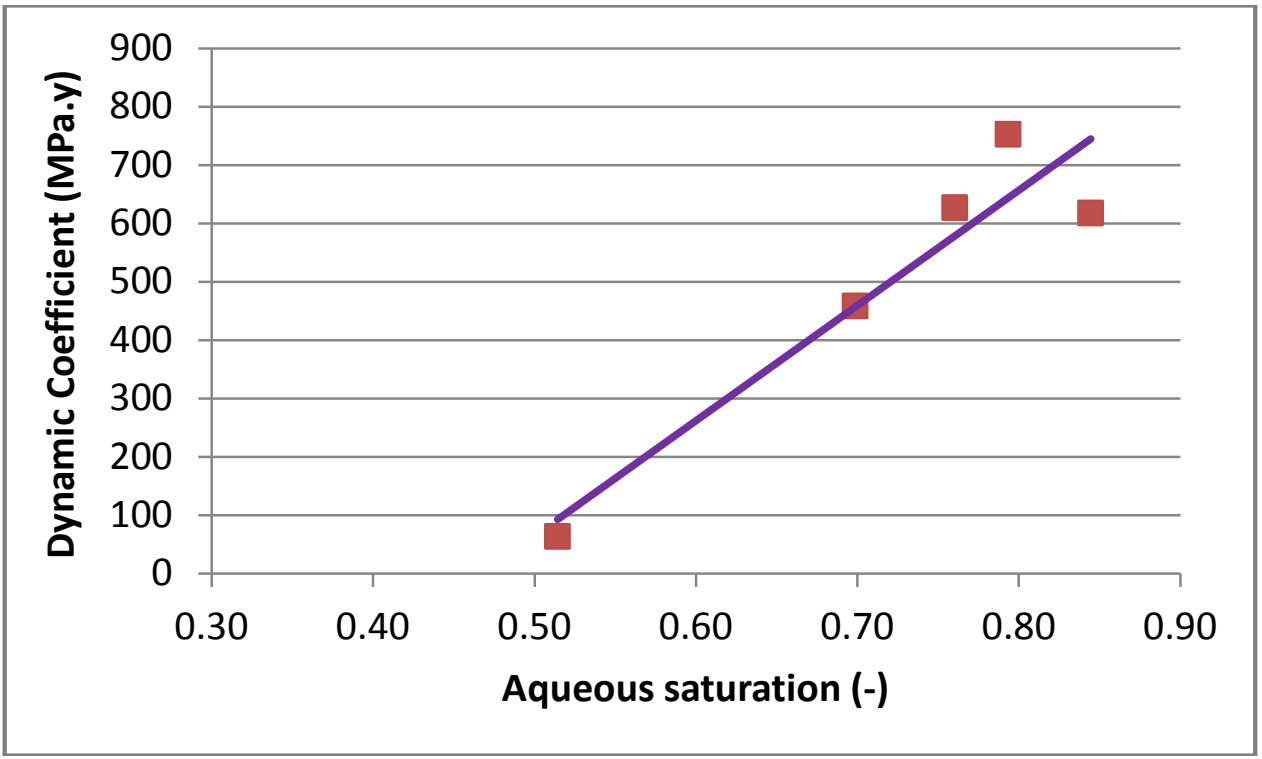

Figure 11. Dynamic Coefficient change with aqueous saturation in a homogeneous coarse sand domain (cases 2 and 10). 


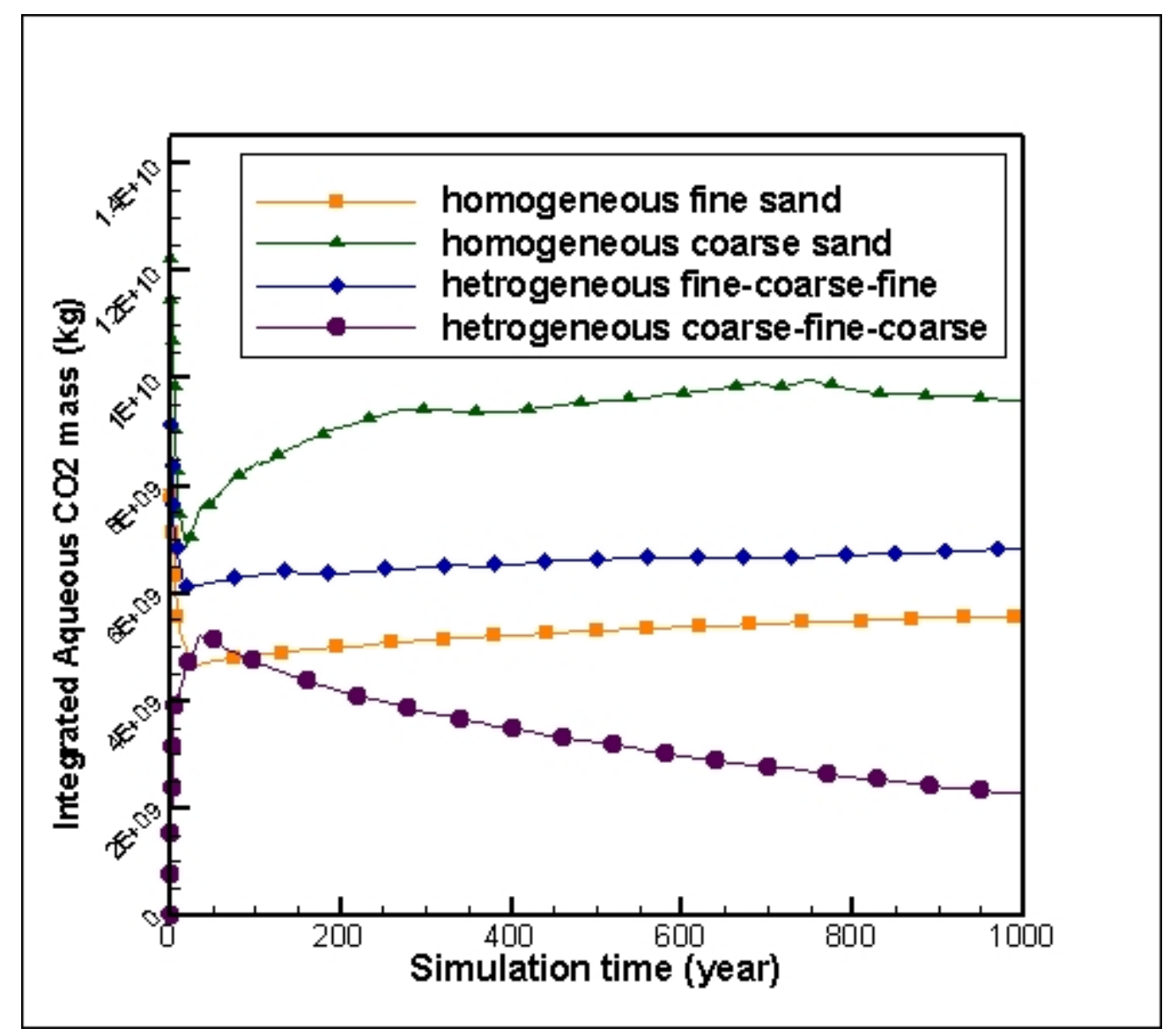

Figure 12. Integrated aqueous change for homogeneous and heterogeneous domains (cases 1, 2, 7 and 8) at radial distance of $200 \mathrm{~m}$ and altitude of $40 \mathrm{~m}$ 


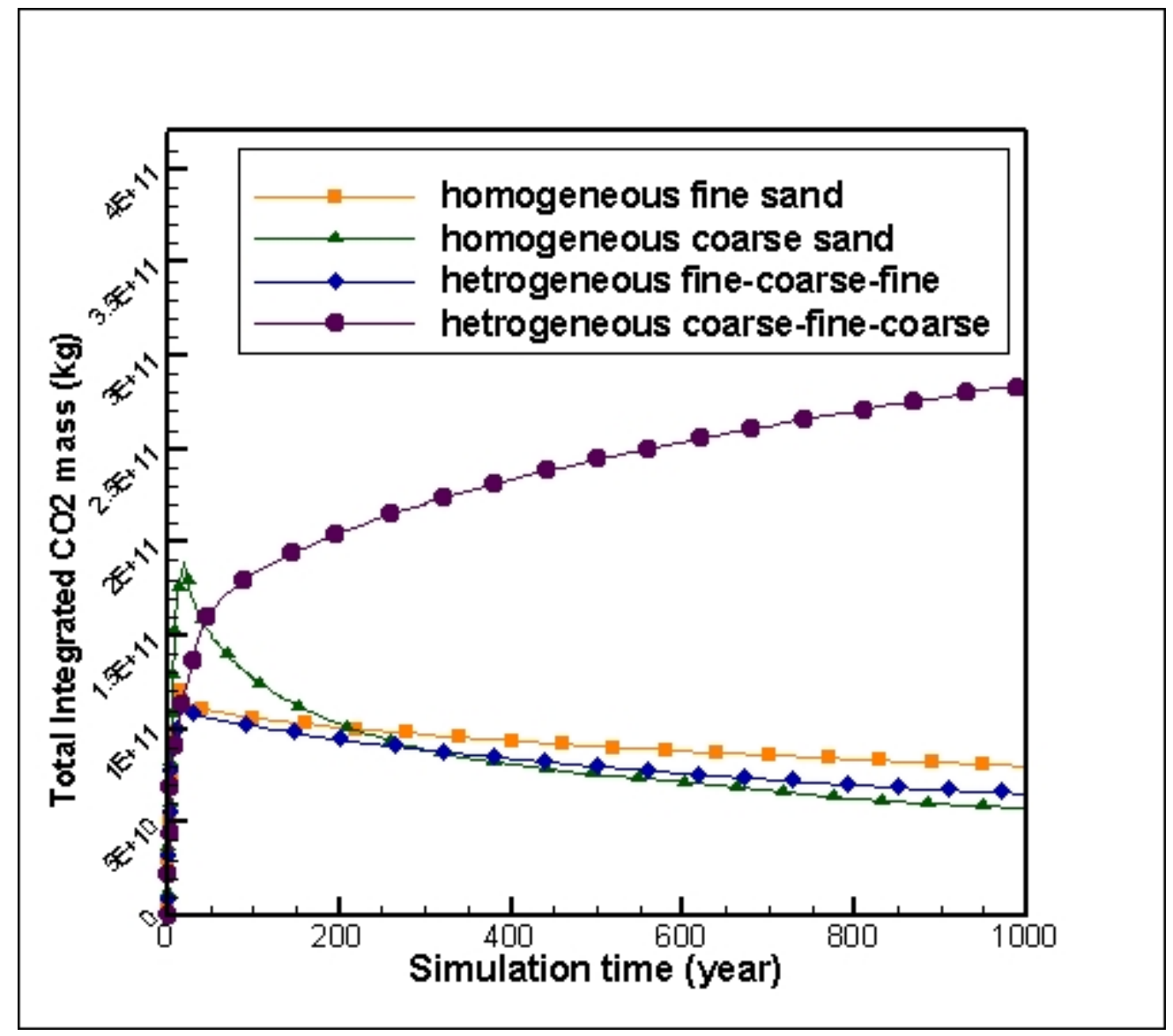

Figure 13. Total Integrated $\mathrm{CO}_{2}$ profiles for homogeneous and heterogeneous domains (cases 1, 2, 7 and 8) at radial distance of $200 \mathrm{~m}$ and altitude of $40 \mathrm{~m}$. 


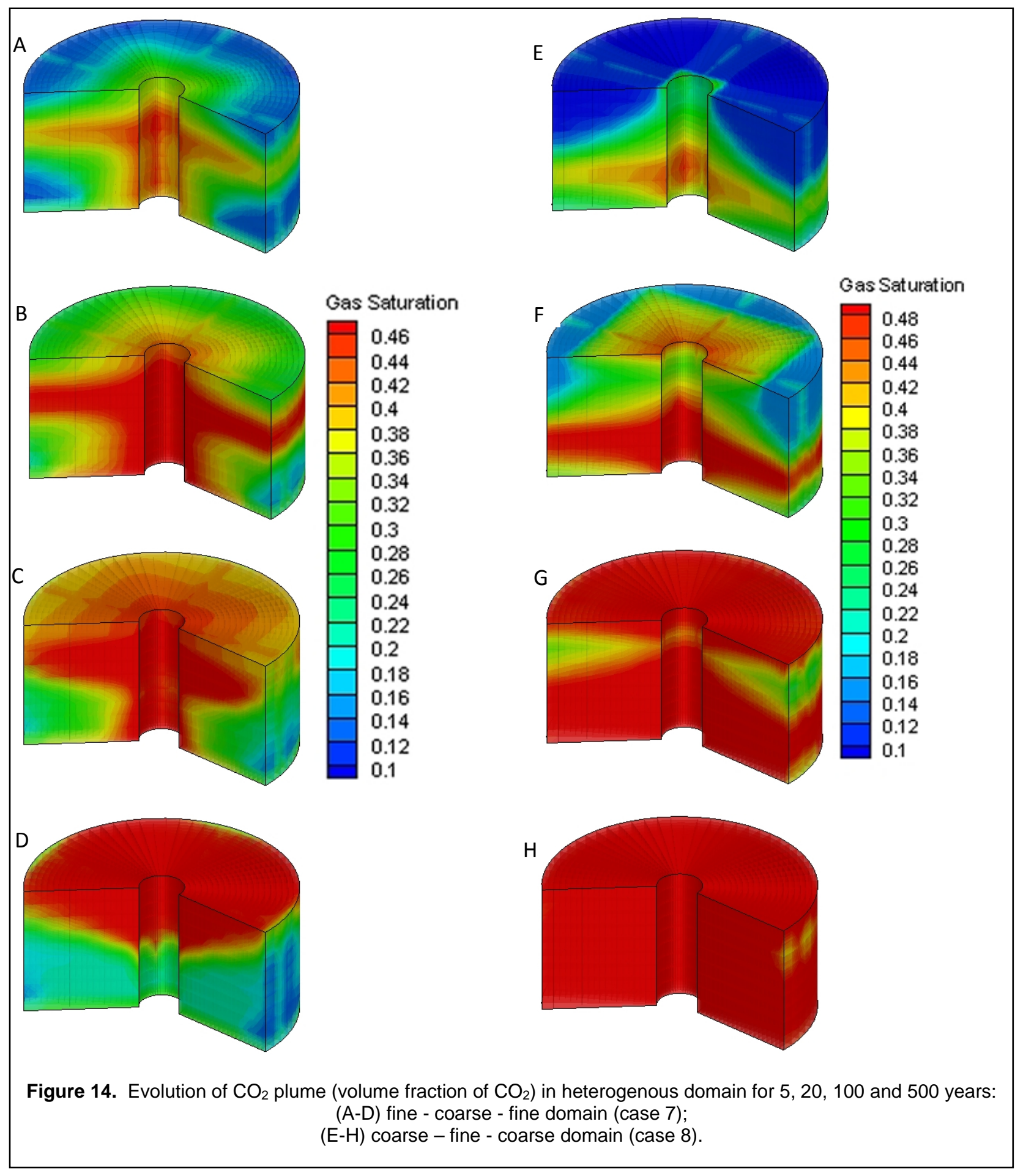

